\title{
ESTRATÉGIAS PARA A REVITALIZAÇ̃̃o DE LÍNGUAS AMEAÇADAS E A REALIDADE BRASILEIRA
}

\author{
Luiz AMARAL (DD \\ University of Massachusetts Amherst (UMass Amherst)
}

\section{○}

OPEN ACCESS

EDITORES

- Marcus Maia (UFRJ)

- Bruna Franchetto (UFRJ)

\section{AVALIADORES}

- Kristine Stenzel (UFRJ)

- Liliana Sánchez (UIC)

DATAS

- Recebido: 07/06/2020

- Aceito: 09/10/2020

- Publicado: 31/12/2020

\section{COMO CITAR}

AMARAL, Luiz. (2020). Estratégias para a revitalização de línguas ameaçadas e a realidade brasileira. Cadernos de Linguistica, v. 1, n. 3, p. 01-44.

\section{RESUMO}

É hora de encararmos com seriedade e dedicação as demandas dos povos falantes de línguas indígenas brasileiras. 2019 foi o Ano Internacional das Línguas Indígenas e devido ao grande sucesso desse chamado à ação, no início de 2020, a Assembleia Geral das Nações Unidas aprovou a declaração da Década Internacional das Línguas Indígenas (2022 - 2032). Como nós, pesquisadores que estamos na academia, vamos responder a esse chamado? Este texto é um convite a uma reflexão sobre como estabelecer de forma central e definitiva a área de estudos da revitalização linguística no Brasil. Ele traz um panorama de como a área vem se organizando em outras partes do mundo e sugere alguns temas que podem servir como objeto de pesquisa em programas de linguística, antropologia e educação. A bibliografia apresentada visa introduzir temas centrais da área ao leitor falante de português e espera-se que a partir das reflexões feitas no texto possamos avançar com pesquisas e ações de revitalização em diferentes contextos de perda linguística no Brasil.

\section{ABSTRACT}

It is time to face the demands by speakers of Brazilian indigenous languages. 2019 was the International Year of Indigenous Languages and, given the enormous success of this call for action, in the beginning of 2020, the General Assembly of the United Nations adopted a 
resolution to establish the International Decade of Indigenous Languages (2022 - 2032). How are we, researchers in academic institutions, going to respond to this call? This paper is an invitation to reflect on how we could definitively establish the area of language revitalization in Brazil. It brings a general view of how this area has been organized in other parts of the world and suggests some themes that could serve as research topics in Linguistics, Anthropology and Education programs. Its bibliography is an introduction to the area to Portuguese speaking readers. Hopefully the discussion presented here will inspire revitalization research projects as well as actions in different language shift contexts in Brazil.

\section{PALAVRAS-CHAVE}

Revitalização Linguística; Línguas Indígenas; Retomada de Línguas Ameaçadas.

\section{KEYWORDS}

Language Revitalization; Indigenous Languages; Endagered Language Reclamation. 


\section{INTRODUÇÃO}

O ano de 2019 foi conclamado pelas Nações Unidas como o Ano Internacional das Línguas Indígenas. Dentre os vários eventos organizados no Brasil e no mundo, tivemos o Viva Língua Viva, do qual tive o imenso prazer em participar. De todas as lições e trocas de experiências que tivemos durante esse encontro, uma das mais importantes foi a constatação de que agora é o momento certo para investirmos no desenvolvimento de uma área de conhecimento reconhecidamente necessária, mas ainda pouco sedimentada: a Revitalização e Manutenção de Línguas Ameaçadas. Até agora, dentro da academia, trabalhos de revitalização têm sido feitos como respostas a demandas específicas, muitas vezes de forma adjacente a pesquisas em áreas consagradas, como a documentação e o estudo de línguas indígenas. Porém, o que se percebe é que relegar as atividades de revitalização a um papel coadjuvante não responde à demanda existente, além de impor restrições às atividades implementas e limitações ao desenvolvimento de conhecimentos específicos que possam auxiliar nos objetivos próprios da revitalização. Duas das perguntas levantadas durante o Viva Língua Viva foram: (i) Como avançar academicamente em trabalhos de revitalização no país? (ii) Quais seriam as consequências para uma segunda edição da conferência em 2021? Um dos objetivos deste artigo é fazer algumas sugestões de como podemos estruturar os estudos de revitalização no Brasil, com base em projetos, práticas e descrições existentes nacional e internacionalmente.

Declarar que a revitalização linguística deve ser uma área específica e, até certo ponto, independente de estudo implica na criação de uma epistemologia própria. Como consequência, temos que estabelecer claramente os problemas e as metodologias de pesquisa para o levantamento de dados e os objetivos acadêmicos. Não podemos nos esquecer que essa área nasce de uma necessidade concreta das comunidades de fala e que temos que evidenciar as relações entre o conhecimento gerado por projetos de pesquisa e o seu impacto na realidade linguística dessas comunidades. Hinton, Huss e Roche (2018) nos lembram que no campo da revitalização "a linha entre a pesquisa e a prática é necessariamente imprecisa"1.

Este artigo traz uma reflexão sobre a área de revitalização linguística, definindo alguns termos usados e apresentando algumas práticas existentes. Nele vemos uma série de referências a trabalhos publicados em inglês, já que um dos objetivos é o de trazer essa literatura para o debate sobre revitalização no Brasil. Algo semelhante deverá ser feito para os trabalhos em espanhol e português. Ele também apresenta algumas observações sobre a realidade brasileira, o estado da arte e possíveis necessidades das comunidades de fala. Para tal, o texto encontra-se dividido nas seguintes seções: 
0. Introdução: Definições e considerações; Vitalidade linguística; Variáveis internas e externas a serem consideradas.

1. O que é necessário para revitalizar uma língua? 1.1 Comunidades de fala. 1.2 Planejamento linguístico. 1.3 Programas de língua para a revitalização. 1.4 Criação de material didático. 1.5 Documentação para a revitalização.

2. Alguns exemplos de programas de revitalização. 2.1 Programas de imersão. 2.2 Programas bilíngues ou de imersão parcial. 2.3 Ensino de segunda língua. 2.4 Programa mestre-aprendiz. 2.5 Práticas comunitárias e familiares. 2.6 Modelos de retomada de línguas adormecidas.

3. A revitalização linguística no Brasil. 3.1 Os desafios no Brasil. 3.2 Algumas áreas de especialização.

4. Conclusão.

Apesar do campo da revitalização ser bastante interdisciplinar, com influências da linguística, linguística aplicada, antropologia linguística, sociologia, educação, psicologia, ciências políticas, entre outras áreas, este artigo focará no papel das áreas mais relacionadas à linguística neste contexto. Ao final, vemos algumas sugestões para avançarmos na discussão sobre como a academia em geral e os programas de linguística em particular podem contribuir para o desenvolvimento dos estudos em revitalização.

\section{DEFINIÇÕES E CONSIDERAÇÕES}

Expressões como "revitalização", "manutenção", "retomada" e até "sustentação linguística" têm sido usadas com frequência para descrever atividades, projetos e práticas que têm como objetivo apoiar o uso de línguas ameaçadas e minorizadas ${ }^{2}$, como as línguas indígenas brasileiras. Vemos que vários autores usam esses termos com conotações às vezes ligeiramente distintas. Uma interpretação mais restrita do termo revitalização linguística nos leva a uma definição onde entendemos revitalização como o reestabelecimento de uma língua que deixou de ser usada por uma comunidade de fala. O problema dessa interpretação restrita é que ela descreve muito poucos casos do universo que queremos abarcar com nosso trabalho. Cada comunidade de fala tem histórias e experiências distintas, o que faz com que a descrição e as características do grau de perda linguística sejam únicas para cada caso. Com a necessidade de ser mais específicos, vários autores começam a usar termos como "manutenção linguística" para descrever casos onde a língua ainda é falada pela comunidade e transmitida para (pelo menos uma parte das) futuras gerações, em contraste com o termo "retomada linguística”, onde a língua já não é falada, pelo menos por uma parte significativa da comunidade.

2 O termo "língua minorizada" difere da expressão “língua minoritária”, já que por "minorizada" entende-se a situação de uma língua que além de ser falada por uma minoria é também marginalizada, perseguida ou banida por grupos sociais majoritários, governos ou instituições. 
Segue então a necessidade de um termo mais amplo para abarcar todos esses casos e poder incentivar o diálogo de experiências. Internacionalmente o termo "revitalização linguística" (/anguage revitalization, em inglês) tem sido escolhido por vários autores para se referir de forma mais ampla a essas distintas realidades (HINTON; HALE, 2001). Usarei então o termo com essa mesma conotação. Ou seja, chamarei de "revitalização" a área de ação e estudo que visa manter, revitalizar, apoiar ou retomar línguas ameaçadas, adormecidas e/ou minorizadas. Isso não quer dizer que as diferenças entre esses cenários não sejam importantes. Simplesmente procuro um termo que se refira de forma ampla a esse campo de atuação. Também usarei o termo "língua (sendo) revitalizada" para me referir a língua alvo de um processo de revitalização, não importando o grau de perda linguística associado a essa língua.

É importante lembrarmos que quando falamos de revitalização linguística, o foco principal está na língua e o objetivo é manter o seu uso. Ou seja, em um sentido estrito do termo, não importa a maneira como a língua esteja sendo mantida, o que importa é que existam pessoas falando a língua. Por isso é sempre bom lembrarmos que a revitalização linguística é, pelo menos teoricamente, independente de outras áreas de atuação como o planejamento linguístico, a educação formal, a documentação ou a descrição da língua. Os exemplos mais óbvios de línguas ameaçadas que mantém seu grau de uso sem nenhum tipo de apoio educacional ou de planejamento linguístico são os das línguas faladas por populações isoladas da Amazônia. Porém, existem casos de grupos com alto grau de manutenção linguística, apesar de manterem um contato constante com populações que não falam a sua língua e onde o sucesso da transmissão intergeracional não pode ser atribuído a um sistema escolar formal, como é o caso dos Apyãwa no Tocantins (DIAS DE PAULA; TAPIRAPÉ, 2017). Desta forma, mesmo sendo comum no Brasil ver esforços de revitalização atrelados ao sistema escolar e o ensino formal (FERREIRA, 2001; dos SANTOS MILHOMEM, 2011; ROCHA D’ANGELIS, 2014), existem várias experiências ao redor do mundo onde a revitalização ocorre de forma completamente independente da educação escolar. De maneira geral, podemos dizer que a educação escolar indígena pode ocorrer perfeitamente sem nenhum trabalho de retomada linguística, e a recíproca também é verdadeira. Existem programas de revitalização que funcionam de forma independente do sistema escolar, como veremos na seção 1. Em geral, é importante enfatizar que essas são duas áreas distintas, mas que podem e devem colaborar.

Um outro conceito central no trabalho de revitalização é o de "comunidade de fala".

Mais além da noção laboviana de speech community, o que nos interessa aqui é ter um termo com o qual possamos nos referir aos atuais e/ou potenciais falantes de uma 
determinada língua ameaçada, ou de uma das suas variantes linguísticas ${ }^{3}$. Reparem que a expressão "potenciais falantes" tem uma implicação importante não somente do ponto de vista prático (quem irá revitalizar a língua?), mas em muitos casos também estrutural (a quem a língua pertence?). Hinton, Huss e Roche (2018) vão além, e afirmam que no caso da revitalização linguística, a comunidade de fala não precisa nem sequer estar em um mesmo local físico. Ela pode se estabelecer em comunidades diaspóricas e em alguns casos se constituir virtualmente através da internet. Essa comunidade de fala também não precisa refletir a totalidade da população de uma determinada comunidade indígena. Ela pode ser um subgrupo de pessoas que valorize o tema e que esteja disposto a desenvolver práticas de revitalização da língua. É bom lembrar que no caso do Brasil temos uma das menores concentrações de populações indígenas da América Latina e, como afirmam Leite e Franchetto (2006), a densidade linguística em território nacional é muito baixa, com uma média de menos de 200 falantes por língua. As características extralinguísticas da comunidade de fala vão determinar uma série de decisões a respeito das características e possibilidades de implementação de diferentes tipos de projeto de revitalização, como veremos na seção 2. Usarei então o termo "comunidade de fala" com essa conotação mais ampla que inclui não somente os atuais falantes, mas também grupos de pessoas que se sintam representadas por uma determinada língua ancestral e que estejam disponíveis e interessadas em projetos de retomada linguística.

Justamente porque as comunidades de fala apresentam experiências, histórias, objetivos e recursos únicos, é que devemos lembrar que não existe e não deve existir um só objetivo para todos os projetos de revitalização. Muitas vezes, quando pensamos em revitalizar uma língua, acreditamos que só pode haver uma medida única de sucesso que seja a volta do uso da língua pela comunidade de fala semelhante ao que foi um dia observado em antigas gerações. Essa medida não só é impossível de ser alcançada, pelas diferenças óbvias nos contextos históricos, como ela não é desejável, pois está baseada em uma ideia de que a comunidade de fala pode parar no tempo, o que certamente dificultará a prosperidade futura das línguas revitalizadas. Além disso, essa medida estrita de sucesso muito provavelmente gerará mais frustração por parte dos participantes, tanto durante o projeto quanto na hora de avaliar os resultados. Assim, cada projeto tem de definir os seus objetivos e suas medidas de sucesso de forma realista. Ao estudar algumas das experiências mencionadas na seção 2 , vemos claramente que quanto mais realistas e mensuráveis sejam os objetivos de um projeto, mais chances de sucesso ele pode ter. Por isso, são tão importantes os casos como os dos Kaurna, na Austrália (AMERY, 2016), que conseguiram

3 Reparem que muitas das discussões em sociolinguística sobre a definição do conceito de comunidades de fala assim como os critérios usados para classificar certas comunidades de fala podem ser usados aqui (LABOV, 2001; HUDSON, 1996). Porém, existem outros pontos específicos relacionados à realidade das línguas minorizadas e a questões de revitalização que devem ser considerados ao usarmos esse termo. 
retomar alguns usos cerimoniais de sua língua em cantos, falas de lideranças e expressões cotidianas, assim como alguns grupos de Papua Nova Guiné que usam a língua ao aprenderem as danças tradicionais (HARRIS, 1977). No caso dos Kaurna, a sua língua, que já não era mais falada, foi retomada de forma a suprir seus objetivos culturais, apesar de não ser a língua usada para transações cotidianas na sociedade. Voltaremos ao tema dos objetivos e estruturas de programas de revitalização na seção 1.2, mas é importante abandonarmos o "mito do tudo ou nada" para projetos de revitalização.

\section{VITALIDADE LINGUÍSTICA}

Avaliar a vitalidade linguística é uma das ações necessárias para propormos práticas de revitalização. Uma observação menos técnica pode dar a impressão de que o critério do número total de falantes é suficiente para garantir o futuro de uma determinada língua. Porém, as variáveis usadas para estabelecer o grau de vitalidade linguística levam em consideração muitos outros fatores. Existem vários trabalhos que utilizam diferentes metodologias para avaliar a vitalidade das línguas, entre eles Fishman (1991) e Tsunoda (2005). Ao invés de nos determos a uma análise mais detalhada das diferentes metodologias, veremos rapidamente a sugestão de um grupo ad hoc da UNESCO, formado por diferentes especialistas, que em 2003 preparou uma lista de nove fatores para medir a vitalidade de uma língua.

Como vemos na tabela 1 , os três primeiros fatores estão relacionados à quantidade de falantes de uma língua e à qualidade da transmissão linguística dentro da comunidade de fala. O primeiro fator observa diretamente se crianças e jovens estão falando a língua ameaçada, enquanto os fatores 2 e 3 descrevem o número absoluto de falantes e a sua proporção diante do número de membros da comunidade de fala. Os cinco fatores seguintes dizem respeito a algumas características do ambiente onde a língua é falada. Os fatores 4 e 5 observam o uso atual da língua dada as situações comunicativas em que ela esteja sendo usada, assim como a capacidade atual da língua de se adaptar a novos domínios de uso que reflitam as novas necessidades de futuras gerações. Aqui vale ressaltar que o critério 5 mais uma vez nos mostra que processos de revitalização bem-sucedidos não são os que tentam retomar o uso da língua semelhante ao dos antepassados, e sim os que propõem revitalizar a língua para as futuras gerações de falantes, incluindo seus usos em novas mídias. O critério 6 reforça o possível papel que a educação formal pode ter em processos de revitalização4 4 . Já os critérios 7 e 8 apontam para a importância das atitudes externas e internas no uso da língua. Veremos mais adiante que entre os diferentes tipos de desafios que a revitalização pode encontrar, o

4 É importante lembrar que a UNESCO tem uma longa tradição de incentivar programas de letramento através do mundo para combater a desigualdade social e a pobreza. Por isso a inclusão na sua lista do letramento como sendo importante para a manutenção de línguas ameaçadas deve ser vista dentro de uma perspectiva histórica e cultural dessa entidade e não como um fator chave para todos os casos de revitalização. 
único que realmente inviabiliza qualquer trabalho em prol da língua é o de uma comunidade de fala que tem uma atitude negativa com relação à revitalização. O último fator considera a quantidade e a qualidade da documentação linguística disponível. Esse fator aponta obviamente as necessidades mais prementes das comunidades em contextos onde a língua já não é mais falada, ou é falada por um grupo muito pequeno de seus membros.

\begin{tabular}{|c|l|l|}
\hline Fator & \multicolumn{1}{|c|}{ Descrição } & \multicolumn{1}{c|}{ Área } \\
\hline 1 & Grau de transmissão intergeracional & Número de falantes \\
\hline 2 & Número absoluto de falantes & Número de falantes \\
\hline 3 & Proporção de falantes na população & Número de falantes \\
\hline 4 & Domínios de uso da língua & Uso da língua \\
\hline 5 & Adaptação a novos domínios & Uso da língua \\
\hline 6 & Materiais existentes para educação & Educação \\
\hline 7 & Políticas públicas e reconhecimento institucional & Atitudes (externas) \\
\hline 8 & Atitudes linguísticas da comunidade & Atitudes (internas) \\
\hline 9 & Quantidade e qualidade da documentação linguística. & Documentação \\
\hline
\end{tabular}

Tabela 1. Fatores de vitalidade linguística de uma língua.

Os critérios listados acima permitem a avaliação do grau de perda linguística em uma determinada comunidade de fala. Segundo a UNESCO (2003), a vulnerabilidade de cada língua pode ser descrita em seis graus.

\begin{tabular}{|c|c|c|}
\hline 5 & Em segurança/ não ameaçada & $\begin{array}{l}\text { A língua é falada por todos na comunidade e está sendo transmitida para } \\
\text { as novas gerações. Ela é usada na maioria dos contextos de uso e está } \\
\text { adequada às necessidades comunicativas dos seus falantes. Não existe } \\
\text { ameaça de ser substituída por outra língua socialmente dominante. }\end{array}$ \\
\hline 4 & Vulnerável & $\begin{array}{l}\text { O uso da língua pelas gerações mais jovens é menos constante. Nem to- } \\
\text { das as famílias usam a língua em casa. O uso da língua está restrito a } \\
\text { alguns domínios de fala. }\end{array}$ \\
\hline 3 & Definitivamente em perigo & $\begin{array}{l}\text { A língua não é transmitida como primeira língua às crianças em casa. Os } \\
\text { falantes mais jovens da língua já são adultos. Os jovens e as crianças } \\
\text { mesmo quando escutam a língua não a usam para se comunicar. As si- } \\
\text { tuações de uso comuns da comunidade não se dão na língua ameaçada. }\end{array}$ \\
\hline 2 & Severamente em perigo & $\begin{array}{l}\text { A língua é falada apenas pela geração dos avós e existem muito poucos } \\
\text { falantes adultos da língua. A geração dos pais pode entender a língua } \\
\text { oral, mas não a usam. A língua não é mais transmitida para as crianças. } \\
\text { A língua já não é usada pela comunidade em suas atividades diárias. }\end{array}$ \\
\hline 1 & $\begin{array}{l}\text { Perigo crítico de desapareci- } \\
\text { mento }\end{array}$ & $\begin{array}{l}\text { Existem apenas alguns falantes muito idosos da língua. Esses anciãos mui- } \\
\text { tas vezes só têm conhecimento parcial do vocabulário e já não usam a lín- } \\
\text { gua em nenhum contexto. Adultos, jovens e crianças não falam a língua }{ }^{5} \text {. }\end{array}$ \\
\hline 0 & Extinta & Não existem mais falantes vivos. \\
\hline
\end{tabular}

Tabela 2. Graus de perda linguística segundo a UNESCO.

Como veremos na seção 1.2, os elementos que nos ajudam a fazer uma análise da vitalidade linguística também podem nos ajudar nas etapas do planejamento linguístico recomendado antes de se iniciar um projeto de revitalização. É também importante lembrar que

5 O caso Guató no Brasil parece ser um exemplo de uma língua em perigo crítico de desaparecimento (FRANCHETTO; GODOY, 2017). 
recentemente temos visto projetos de revitalização com línguas que foram consideradas extintas. Muitos ativistas linguísticos, falantes e pesquisadores têm começado a usar o termo "língua adormecida" para descrever estas línguas classificadas pela UNESCO como "extintas".

\section{VARIÁVEIS INTERNAS E EXTERNAS A SEREM CONSIDERADAS}

Segundo Grenoble e Whaley (2006), a revitalização envolve o reequilíbrio das forças que geraram a perda linguística em primeiro lugar. É importante ter clareza de que as línguas se encontram ameaçadas por distintas razões históricas, políticas, sociais e econômicas, por isso quanto mais informações tenhamos sobre as causas da perda linguística mais é possível desenvolver estratégias para reverter essas perdas. Existem motivos externos e também internos para essa perda e saber reconhecer essas diferenças é crucial. Na maioria das vezes, as variáveis externas têm um impacto significativo nas internas/locais, porém muitas vezes a solução se encontra em mudanças das variáveis internas para superar as adversidades vindas de fora. Com base no segundo capítulo de Grenoble e Whaley (2006), vejamos quais são algumas dessas variáveis.

As variáveis externas, também chamadas de macro variáveis, são forças que impactam a comunidade de fala, mas que muitas vezes estão fora do seu controle. Grenoble e Whaley (1998) atribuem essas variáveis externas a diferentes "esferas de influência: local, regional, nacional e extranacional". A variável extranacional mais relevante no momento histórico em que vivemos é a globalização e a ascensão político-econômica de certos países ou grupos de países, o que leva ao prestígio internacional de certas línguas francas, também chamadas de línguas globais, como inglês, chinês, árabe e espanhol. No caso específico do inglês, temos o fenômeno de uma língua que ganhou o status de língua franca internacional, o que gera uma pressão muito grande sobre sistemas educacionais ao redor do mundo, incluindo em comunidades de línguas minorizadas, para que o inglês faça parte do currículo nas escolas, reduzindo ainda mais o tempo disponível para o trabalho com a língua revitalizada. Além disso, a disponibilidade de informação técnica sobre alguns temas fica muitas vezes restrita à língua inglesa e é necessário um esforço consciente por parte de diferentes instituições e indivíduos para que essa informação seja disseminada em outras línguas ${ }^{6}$.

A nível nacional e muitas vezes regional, as diferentes políticas públicas que afetam diretamente o planejamento linguístico das comunidades de fala têm um impacto direto na revitalização. No Brasil, o movimento que vemos de reconhecimento oficial a nível municipal

6 Reparem que uma parte significativa do conhecimento apenas disponível em inglês não é produzida por falantes nativos desse idioma e não vem de países onde o inglês seja a língua oficial. Basta ver a quantidade de pesquisadores brasileiros que publicam frequentemente em inglês. Por isso é importante incentivar as publicações em português e, quem sabe, em um futuro próximo, nas próprias línguas que estão sendo revitalizadas. 
de certas línguas indígenas (SILVA, 2016), assim como todos os esforços derivados da Constituição de 1988 para promover as culturas e línguas indígenas no país são passos importantes para o apoio às línguas ameaçadas (BRAGGIO, 2002). Porém, não podemos nos enganar e achar que algumas mudanças em leis e estatutos são capazes de solucionar o problema. $\mathrm{O}$ apoio financeiro e logístico para as atividades de revitalização é a única maneira de fazer com que políticas públicas tenham algum impacto significativo. Na África do Sul, por exemplo, existem 11 línguas oficiais, mas só duas são realmente usadas administrativamente (inglês e afrikaans), e apesar das outras línguas terem um número significativo de falantes, elas se encontram ameaçadas pelo domínio das duas línguas que contam com práticas públicas que reforçam sua importância (SKUTNABB-KANGAS, 2000). Outros fatores que afetam as comunidades de fala a nível nacional e regional incluem atitudes linguísticas com relação às línguas minorizadas, políticas educacionais e até uma possível autonomia outorgada a órgãos públicos, como as secretarias de educação ou a FUNAl, no caso brasileiro. Também, a nível regional elementos como densidade linguística, a existência de outras línguas regionais e possíveis disputas entre diferentes grupos podem afetar diretamente iniciativas de revitalização.

Se existe algum tipo de consenso entre especialistas em revitalização linguística é o de que os projetos construídos pela comunidade e para a comunidade são os que têm maior chance de sucesso. Por isso, as chamadas micro variáveis, ou variáveis locais e internas às comunidades de fala são fundamentais.

Existem muitas variáveis a nível local que afetam a vitalidade de uma língua e a sua possibilidade de revitalização. Nossa lista não é exaustiva, mas simplesmente representativa de características observadas em distintas comunidades que tentam revitalizar suas línguas. A primeira delas é o conjunto de atitudes linguísticas presentes na comunidade. É comum observar o impacto das atitudes linguísticas de grupos externos nas atitudes da comunidade de fala. Porém, é também importante ressaltar que quanto mais se intensifica a noção de que a revitalização faz parte de um movimento de resistência e sobrevivência da comunidade, muitas vezes uma atitude linguística negativa que venha de fora se defronta com um fortalecimento das atitudes positivas de dentro da comunidade (HINTON; HUSS; ROCHE, 2018). A atitude linguística influencia diretamente dois fatores internos importantes: a motivação e a disponibilidade dos participantes para projetos de revitalização. Assim como a perda linguística é muitas vezes fruto de ações contínuas e constantes que vão minando pouco a pouco o uso e a transmissão intergeracional de uma língua, o processo de revitalização também requer ações cujos frutos serão mais significativamente 
mensuráveis a longo prazo. Por isso uma real avaliação da motivação e da disponibilidade dos participantes é vital para o sucesso do trabalho?

Outros dois fatores internos importantes estão relacionados aos recursos existentes, tanto recursos humanos como financeiros. No que diz respeito a recursos humanos é importante enumerar os participantes dos projetos e as suas capacidades técnicas para a colaboração. Existem falantes fluentes? Qual o grau de formação acadêmica desses falantes? Eles estão motivados e disponíveis? Da mesma forma é crucial saber que tipos de recursos financeiros ou apoio de parceiros estarão disponíveis. Como vemos na seção 2, alguns dos programas mais bem sucedidos foram os que contaram com participantes dentro da comunidade extremamente engajados, que foram buscar, muitas vezes por conta própria, os conhecimentos necessários e as parcerias com entidades e pessoas externas à comunidade que proporcionaram o apoio técnico, logístico ou financeiro para o sucesso de seus projetos de revitalização.

Grenoble e Whaley (2006) também citam duas outras variáveis internas que, segundo elas, têm um impacto significativo em projetos de revitalização. A primeira é a religião. Elas explicam que as religiões e os rituais religiosos tradicionais oriundos de práticas comunitárias muitas vezes são os últimos bastiões de uso e defesa da língua. Por outro lado, as religiões vindas de fora, sobretudo em países onde não existe uma separação clara entre estado e religião, podem impactar as atitudes linguísticas dos falantes e a sua predisposição à manutenção de suas línguas ancestrais. A outra variável interna relevante é o grau de letramento da comunidade. Segundo as autoras, comunidades que queiram revitalizar suas línguas e que estejam inseridas em um contexto cultural onde o letramento na língua dominante é crucial para os indivíduos, como no caso Maori da Nova Zelândia, a possibilidade de letramento na língua revitalizada vai ser um fator central no processo de revitalização. Elas dedicam dois capítulos de seu livro à questão do letramento na revitalização. Outros autores também reforçam a noção de que a escrita pode facilitar processos de revitalização, principalmente nos casos onde as ações estejam relacionadas a programas educacionais formais (HORNBERGER, 1996, 2008). Devemos ressaltar que o caso brasileiro que não é considerado pelas autoras aqui mencionadas, pode apresentar contextos bastante distintos dos discutidos na literatura citada e será necessário fazer uma análise mais detaIhada de cada grupo para que possamos determinar a importância do desenvolvimento das habilidades de leitura e escrita dentro das atividades previstas para a revitalização.

Claro que tanto as macro como as micro variáveis não existem em um vácuo de forma independente. Umas afetam as outras e as condições externas a uma comunidade de fala

\footnotetext{
7 Reparem que estamos falando dos "participantes do projeto" e não da comunidade de forma genérica. Se existe um grupo reduzido de participantes com atitudes positivas à revitalização é possível que seu trabalho sirva para modificar as atitudes e percepções dos demais membros da comunidade.
} 
podem impedir qualquer tipo de ação interna de apoio à língua. O fundamental é pensar em como organizar o conhecimento que temos sobre essas variáveis para podermos estudá-las de forma mais sistemática e cada vez mais aprimorar as práticas que visam apoiar a sobrevivência de línguas minorizadas.

\section{O QUE É NECESSÁRIO PARA REVITALIZAR UMA LÍNGUA?}

É impossível responder à pergunta no título desta seção de forma uniforme para todas as línguas, comunidades de fala e contextos sociais, políticos e históricos. Além disso, para a maioria das línguas minorizadas essa é uma pergunta nova. Apesar da existência de experiências de revitalização em algumas partes do mundo já durar algumas décadas, em outras partes, como no Brasil, ainda temos muito trabalho pela frente se quisermos entender e estabelecer uma série de práticas que possam levar a processos bem-sucedidos de revitalização linguística.

Tendo em vista o atual estado da arte, esta seção tem dois objetivos. O primeiro é o de começar a organizar uma resposta à pergunta feita no título fazendo um levantamento de alguns elementos, temas e questionamentos que têm sido usados em diferentes pesquisas e por diferentes programas de revitalização. O segundo objetivo é o de tentar delinear ideias para temas de pesquisa e atuação que possam ajudar na construção de uma área de estudos em revitalização linguística. Ou seja, a ideia é promover um diálogo epistemológico que facilite o avanço acadêmico da revitalização linguística como disciplina. Obviamente, cada um dos temas listados aqui merece uma abordagem muito mais ampla e detalhada que iria além do escopo e das capacidades físicas deste artigo. Contudo, espero que as fontes citadas sirvam de inspiração a outros pesquisadores para que possamos avançar como comunidade acadêmica interessada no tema.

\subsection{COMUNIDADES DE FALA}

Revitalizar uma língua sem uma comunidade de fala é impossível. O máximo que podemos fazer é documentá-la e tentar mantê-la viva com poucos falantes esperando que a oportunidade apareça (ver seção 2.4). Como mencionado na seção "Definições e considerações", vamos usar o termo "comunidade de fala" com uma conotação ampla que inclui não somente os atuais falantes, mas também grupos de pessoas que se sintam representadas por uma determinada língua ancestral e que estejam disponíveis e interessadas em projetos de retomada linguística. 
É importante enfatizarmos que a revitalização de uma língua começa e termina com a comunidade de fala. A grande maioria dos autores aponta como o principal fator de sucesso ou fracasso de programas de revitalização o envolvimento, disponibilidade e perseverança de membros das comunidades de fala afetadas pela perda linguística (FISHMAN, 1991; HINTON; HALE, 2001; TSUNODA, 2005; GRENOBLE; WHALEY, 2006). Com relação aos pesquisadores, sejam eles membros ou não da comunidade, qualquer atividade que se queira iniciar para revitalizar uma língua tem que ser em colaboração direta com membros dessa comunidade (CZAYKOWSKA-HIGGING, 2009; DOBRIN, 2008; DWYER, 2006, 2010; RICE, 2006, 2010, 2011). Ou seja, do ponto de vista da pesquisa, precisamos entender certas características culturais, históricas e linguísticas sobre o grupo de falantes para termos condições de implementar um conjunto de práticas que levem a revitalização, sobretudo no caso brasileiro onde o histórico de contatos violentos e o uso da educação formal como instrumento de genocídio cultural marcaram uma boa parte da história dos programas educacionais para populações indígenas (FREIRE, 2014). Pesquisas antropológicas que gerem certos tipos de informações sobre a comunidade de fala nos permitem avaliar elementos específicos para cada projeto, como por exemplo: um diagnóstico das condições locais para a implementação de atividades de revitalização, a escolha do tipo de programa e as características das atividades a serem desenvolvidos, a capacidade de enumerar objetivos factíveis com relação às variáveis locais, etc. O que necessitamos é que temas relacionados ao uso da língua e atitudes linguísticas sejam inseridos em pesquisas etnográficas para que elas possam fornecer os dados que precisamos para contexto da revitalização linguística.

\subsection{PLANEJAMENTO LINGUÍSTICO}

O planejamento linguístico (language planning) tem servido como peça fundamental em diversos programas de revitalização de línguas ameaçadas em diferentes contextos (HORNBERGER, 2006, 2008; McCARTY, 2018; LO BIANCO, 2018). O termo planejamento linguístico remete muitas vezes a ações governamentais com um impacto significativo sobre determinadas populações e seus sistemas educacionais. Talvez o maior exemplo de planejamento linguístico na história brasileira tenha acontecido no século XVIII, quando uma série de medidas implementadas pelo ministro de D. José I, o Marquês de Pombal, visando aumentar o controle sobre alguns grupos que atuavam nas colônias, incluindo os Jesuítas, faz com que o uso da língua geral fosse severamente reduzido, e que a língua portuguesa começasse a ser usada de forma hegemônica em no território controlado pelos portugueses.

Em contextos mais recentes, no que diz respeito a línguas minorizadas, alguns modelos de planejamento linguístico têm conseguido sedimentar a reversão de processos de perda da língua. Um dos modelos com maior apelo no contexto das línguas indígenas das 
Américas tem sido o do "planejamento linguístico de base comunitária" (CBLP, do termo em inglês community-based language planning). Esse tipo de planejamento é feito a partir da base de falantes e não como uma decisão governamental, dando as comunidades de fala o papel de protagonista no processo de revitalização.

Sallabank (2012) define o termo planejamento linguístico como "ações ou medidas concretas para implementar políticas que sejam definidas como decisões, posições e princípios sobre a língua, sua natureza e seus papeis" (p. 119). McCarty (2018) cita três tipos básicos de atividades de planejamento (p. 23): (i) "o planejamento do status" (como, para quê e em que contextos a língua será usada? A ideia é pensar nos espaços e funções que a língua terá ao ser revitalizada.); (ii) "o planejamento do corpus" (quais as estruturas linguísticas e vocabulário serão usados no processo de revitalização? Isso inclui a preparação de gramáticas, dicionários, oficina de criação de léxico, materiais de ensino, etc.); (iii) "o planejamento da aquisição" (quem vai adquirir a língua? Como? Que habilidades linguísticas esperamos que desenvolvam? Esta etapa inclui a preparação do corpo docente, dos programas de ensino de língua ou qualquer outra estratégia necessária para efetuar a transmissão do conhecimento linguístico). Essas etapas são na maioria das vezes simultâneas e mesmo que não tenhamos um plano construído para pautar nossas ações, vale a pena uma reflexão comunitária usando perguntas que respondam a todas as etapas do processo de revitalização.

Em uma tentativa de organizar formalmente um programa de revitalização linguística, Hinton (2001b) descreve nove passos a serem dados. Pensando na realidade brasileira e nos objetivos desse artigo, eu apresento uma lista adaptada, mas fortemente embasada na lista originalmente descrita por Hinton (p. 6) ${ }^{8}$. Não devemos entender esses passos como uma receita, por isso os apresento na seção sobre planejamento linguístico. O objetivo é usar a descrição desses passos para ajudar a pensar em mecanismos de construção de planos a serem implementados.

- Passo 1: Avaliação das condições e planejamento. O objetivo deste passo é o de fazer um levantamento com relação a situação de uso (real ou potencial) da língua, o número de falantes, as variantes usadas, os recursos existentes, o engajamento da comunidade de fala, etc. É importante ter uma noção das atitudes linguísticas dentro e fora da comunidade e discutir os objetivos do projeto e a sua adequação à realidade. Idealmente devemos estar confiantes de que os objetivos propostos são factíveis.

- Passo 2: Com base na avaliação anterior, organizar os recursos existentes e iniciar a preparação dos materiais necessários, incluindo materiais didáticos. Se a língua só tem falantes idosos, é importante implementar um programa de documentação emergencial. Se a língua ainda tem um grupo de falantes adultos e jovens, é necessário

\footnotetext{
8 É importante frisar que a lista aqui descrita reflete diretamente a lista original de Hinton (2001b) e que as adaptações e comentários acrescentados têm apenas um caráter didático com o objetivo de começarmos uma discussão sobre como os trabalhos de revitalização feitos internacionalmente podem dialogar com a nossa realidade.
} 
documentar e organizar os dados linguísticos para que sirvam aos propósitos da revitalização (ver seção: 1.5).

- Passo 3: Desenvolver programas para a formação do quadro de pessoal que será responsável pelas atividades de revitalização. Hinton enfatiza a importância de se ter um grupo de adultos com conhecimento linguístico suficiente para poder implementar as estratégias de transmissão de conhecimento linguístico. No caso brasileiro, onde os agentes podem ser professores de língua que trabalham em escolas, além da formação linguística básica, é fundamental incluir o aperfeiçoamento com disciplinas que tratem de teorias de aprendizado e metodologias de ensino para capacitá-los a preparar planos de aula e programas de língua.

- Passo 4: Desenvolver, "despertar" e encorajar práticas culturais locais que apoiem e enfatizem o uso da língua como ferramenta central, seja em casa ou na esfera pública. Como vemos na seção 2.5 , essas práticas são muito importantes para que o projeto não fique restrito ao ambiente de educação formal.

- Passo 5: Desenvolver programas de transmissão da língua para os distintos grupos de falantes: crianças, jovens e adultos. A natureza do programa de transmissão linguística vai depender das variáveis locais e dos objetivos (ver seção 2).

- Passo 6: Incentivar o uso da língua nas casas. Criar metodologias de apoio a transmissão linguística a nível familiar. Apoiar as famílias que queiram manter a língua no ambiente doméstico. A seção 2.5 vai apresentar argumentos para reforçar a necessidade do envolvimento das famílias no processo de revitalização linguística.

- Passo 7: Criar mecanismos para que a língua comece a ter um maior impacto na esfera pública, como em atividades políticas, comerciais, midiáticas e educacionais.

- Passo 8: Onde for possível, promover mecanismos de uso da língua fora do domínio local. Promover a língua a nível municipal, regional, estadual e até nacional. Vemos no Brasil alguns casos como o do Nheeengatu que está resgatando seu papel de língua representativa de culturas indígenas de diferentes regiões, ao sair do Alto Rio Negro e se estabelecer em programas educacionais no Baixo Tapajós (ARRUTI; COSTA VIERA; RAMOS da SILVA, 2019). Vale a pena se perguntar que estratégias de planejamento linguístico podem levar o Nheengatu a alcançar ainda maior prestigio e ampliar suas comunidades de fala e seus usos públicos. Para outras línguas, o planejamento linguístico pode incluir o seu ensino e uso em populações regionais não-indígenas desde que a comunidade original acredite que essa ação vá lhes proporcionar benefícios. Este é obviamente um debate complexo que tem que levar em conta a propriedade intelectual e ancestral da língua por parte das populações indígenas, a relação da comunidade com os linguistas e o acesso a essa informação por pessoas de fora da comunidade (SÁNCHEZ, 2016). Do ponto de vista meramente da preservação linguística, é óbvio que quanto maior o número de falantes e funções sociais que uma língua tenha, mais preservada e fora de risco ela estará.

As explicações vistas até aqui podem passar a impressão de que o planejamento linguístico é necessariamente algo muito técnico, complexo e difícil de ser alcançado. Porém, experiências recentes mostram que ele pode começar com uma simples observação da situação na qual a língua se encontra. Existem exemplos onde o planejamento foi feito (ou pelo menos iniciado) por um único indivíduo. No caso Wampanog (Massachusetts, EUA), jessie little doe baird, uma integrante da tribo Mashpee Wampanog, se viu em uma 
situação onde a sua língua já não era falada há mais de um século, mas contava com uma documentação extensa, pois já havia sido usada como língua franca regional em tempos coloniais, o que, na época, incluía a criação de textos escritos. Em 1992, ela decidiu que era sua responsabilidade o "redespertar" da língua de seus ancestrais. Ela começou a coletar documentos, estabeleceu uma colaboração com os linguistas Kenneth Hale and Norvin Richards do Massachusetts Institute of Technology (MIT), começou a aprender a língua e a estudar linguística. Ela desenvolveu materiais didáticos, criou o vocabulário necessário para adaptar a língua aos nossos tempos e em 1997, ela começou a oferecer as primeiras aulas de língua para a sua comunidade. Quase três décadas depois, os Mashpee Wampanog têm uma escola primaria, oferecem aulas de língua para os membros da comunidade, programas de imersão para crianças durante o verão e tem até o seu próprio ninho de língua. Pela primeira vez depois de mais de um século existem crianças que estão crescendo falando Wampanog.

O planejamento linguístico como área de pesquisa e atuação ainda precisa ser desenvolvido de forma consistente no Brasil. Carecemos de projetos que possam, com base em uma metodologia formal, fazer a avaliação, o planejamento e os estudos sobre a implementação de práticas de revitalização. É importante ressaltar que existem trabalhos de revitalização em território nacional, mas academicamente ainda nos falta uma estrutura que nos ajude a encontrar, aprimorar e difundir as melhores práticas para esses trabalhos. O capítulo de Hinton (2001a), além de textos de autoras como Nancy Hornberger (HORNBERGER, 1996, 2006) e Teresa McCarty (McCARTY, 2011, 2013) são ótimas introduções ao tema. É fundamental que mais programas de linguística e antropologia no Brasil incentivem seus alunos tanto da graduação como da pós-graduação a prepararem projetos de pesquisa na área do planejamento linguístico para línguas ameaçadas.

\subsection{PROGRAMAS DE LÍNGUA PARA A REVITALIZAÇÃO}

Hornberger e De Korne (2018) chamam atenção para um questionamento importante no título do seu artigo chamado "Is revitalization through education possible?" (em tradução livre: É possível revitalizar através da educação?). As autoras descrevem o papel que a educação formal teve na destruição das culturas e línguas minoritárias em diferentes partes do mundo, muito semelhante aos objetivos de integração e extermínio das populações indígenas que Braggio (2002) descreve no processo brasileiro. Hornberger e De Korne também afirmam que mesmo depois que as populações locais tomaram as rédeas dos seus processos educacionais, a educação formal por si só não foi capaz de mudar as condições que causam a perda linguística. Porém, elas reconhecem que a educação formal e os programas de língua podem ter um papel imprescindível em certos processos de retomada e manutenção das línguas. Na seção 2.5 vemos como é necessário criar 
situações de uso da língua que estejam desvinculadas dos ambientes educacionais e que o planejamento do status deve responder às necessidades de uso constante da língua. Por isso, temos sempre que ter em mente as vantagens e os limites dos programas de ensino de língua nos processos de revitalização.

Grenoble e Whaley (2006) dedicam o segundo capítulo de seu livro a criação de programas de língua. Nele elas descrevem desde as etapas preliminares para o desenvolvimento de tais programas até uma lista de verificação dos recursos e procedimentos para ser usada durante o processo de criação desses programas. Dentre as etapas preliminares, elas recomendam uma avaliação das condições, atitudes e recursos locais, além de procedimentos para se averiguar as necessidades específicas e estabelecer os objetivos. Elas também enumeram alguns dos problemas que podem ocorrer ao longo do trabalho, com especial ênfase ao desencontro entre os recursos humanos e materiais disponíveis, o real engajamento dos membros da comunidade e os objetivos do programa de revitalização. Em praticamente todos os relatos desse tipo de programa, existem sempre etapas de ajustes. Com certa frequência, podemos ver a frustração ou o desânimo dos participantes. O processo é longo, requer um engajamento por um período de tempo extenso e uma capacidade política de organizar grupos de pessoas entorno de um objetivo comum. Manter a motivação dos grupos envolvidos pode se tornar o maior desafio do projeto. Outros problemas encontrados dizem respeito à propriedade linguística, disputas internas que incluem questões relacionadas aos detentores do saber, estigmas sobre variantes linguísticas e até o preconceito com relação a certos membros da comunidade. Mudanças nas lideranças políticas ou linguísticas podem destruir completamente um projeto de anos. De forma mais direta, a falta de planejamento e formação de pessoal capaz de levar a frente certas atividades também pode ser um desafio.

Com relação as etapas de implementação de um programa, elas vão variar para cada caso. Na seção 1.2 vimos algumas dessas etapas de forma genérica. Os vários exemplos apresentados na seção 2 ilustram os diferentes tipos de programas e a partir deles podemos estabelecer mais diretamente as etapas de preparação. Grenoble e Whaley (2006) enfatizam temas como a expansão do léxico, a criação de material de letramento e a aquisição de segunda língua. Além disso, um dos maiores desafios linguísticos para o desenvolvimento desses programas é o de organizar o conteúdo de forma coerente, em uma sequência que facilite o aprendizado e use um formato de fácil manuseio para alunos e professores. Na próxima seção (1.4) vemos em mais detalhes os elementos necessários para a preparação de materiais didáticos.

Todas essas etapas e metodologias para o desenvolvimento de programas de língua e de seus materiais didáticos são inúteis se não houver a preparação do profissional para trabalhar especificamente com o ensino da língua. Por isso é importante fazer um apelo direto aos programas de formação de professores indígenas que incluam cursos sobre abordagens e metodologias de ensino de língua, com aulas práticas que ofereçam a informação necessária para 
entender a estrutura dos programas de língua, incluindo um grupo vasto de exemplos de atividades pedagógicas para sala de aula baseadas em diversas propostas metodológicas tanto para o ensino de L1 como para L2 ${ }^{9}$. É de suma importância criar um programa de estágio onde os futuros professores possam ver na prática como se dá uma aula de língua para que tenham os subsídios necessários para o seu trabalho. Além dessa formação no ensino de L1 e L2, os futuros professores indígenas também precisam de uma disciplina que trate especificamente da estrutura dos programas de revitalização linguística de línguas ameaçadas, suas práticas, objetivos, exemplos e demandas. Ao estudar os programas de revitalização linguística já implementados (ver seção 2), os professores estarão mais bem equipados para lidar com os desafios encontrados em suas próprias comunidades com relação à manutenção ou resgate linguístico.

Em geral, a melhor maneira de garantir que um programa de língua tenha sucesso e que ele possa contribuir para a revitalização linguística é ter um planejamento linguístico detalhado das atividades com etapas, expectativas e objetivos bem descritos e definidos. Um planejamento bem feito também ajuda a comprometer os diferentes membros da comunidade com as ações propostas e garantir o seu apoio mesmo que haja mudanças nas lideranças tanto do projeto como da comunidade.

\subsection{CRIAÇÃO DE MATERIAL DIDÁTICO}

No contexto brasileiro, muito do que se tem tentado está diretamente relacionado com o ensino-aprendizagem das línguas a serem revitalizadas, por isso é fundamental uma discussão mais aprofundada sobre a criação do material de apoio a programas de revitalização. Amaral (no prelo) propõe uma metodologia para a preparação e avaliação de materiais didáticos que possa responder à grande variação existente em contextos indígenas, onde características culturais e educacionais distintas afetam diretamente as propriedades dos materiais necessários.

Segundo o autor existem seis elementos a serem considerados antes de se começar a preparação de um material didático para a revitalização. Ao tentarmos reunir informações sobre esses seis elementos, conseguimos os subsídios necessários para definir o tipo de material, as suas características básicas e o processo de confecção mais adequado.

- O primeiro desses elementos é o que ele chama de contexto de uso, que remete a características gerais do ambiente onde o material será usado. Para descrevermos em detalhes o contexto de uso do material, todas as informações que pudermos obter sobre a comunidade de fala serão relevantes para o trabalho (ver seção 1.1). Ele também sugere que respondamos a perguntas como: o material será usado em um ambiente de educação formal, como uma escola? Ele será usado por membros da comunidade em

9 Vários programas já incluem disciplinas de introdução a linguística e usam materiais como os apresentados por Maia (2006a, 2006b). É importante estabelecer uma conexão clara entre essas matérias e o ensino de língua. 
programas independentes de revitalização? Que função terá esse material no conjunto das ações propostas? Como esse material será usado?

- O segundo elemento a ser descrito diz respeito aos objetivos pedagógicos. Uma descrição clara dos objetivos pedagógicos a serem alcançados tanto pelo programa de língua quanto pelos materiais é fundamental para que não haja uma decepção com as caraterísticas ou qualidade do material a ser desenvolvido. Infelizmente, ainda vemos projetos de criação de material em contexto indígena onde não existe uma real discussão sobre os objetivos pedagógicos específicos. Obviamente existe sempre um objetivo genérico de ajudar no processo de ensino-aprendizagem para apoiar a manutenção e a revitalização. Porém, como os contextos de uso e os modelos de usuário são sempre muito diferentes de um projeto a outro, é fundamental que haja uma reflexão sobre os objetivos específicos que levem em conta esses elementos. Como veremos na sequência, os objetivos pedagógicos serão fundamentais para determinar as teorias de aprendizado e as abordagens de ensino que iremos adotar. Em suma, sem uma clara definição do que se quer alcançar com um determinado material, obter um resultado satisfatório se transforma em uma questão de sorte, o que leva muitas vezes a uma frustração por parte dos usuários.

- O terceiro elemento é o chamado modelo do usuário ou modelo do aprendiz. Não é difícil perceber a importância de um estudo mais detalhado dos usuários de um material para que ele seja apropriado ao seu público. As características dos usuários que serão coletadas e utilizadas dependem do tipo de material a ser criado, do seu contexto de uso e dos seus objetivos. Existe uma ampla tradição na criação de modelos do usuário para o ensino de línguas, especialmente com relação a ferramentas computacionais de apoio (AMARAL; MEURERS, 2007; MICHAUD; McCOY, 2004). No caso específico da educação escolar indígena em contexto bilíngue, Amaral (2011) defende que o conhecimento linguístico do aprendiz é fundamental para se desenvolver um modelo do usuário que possa informar a escolha das teorias de aprendizado e das abordagens de ensino a serem usadas. São vários os exemplos práticos da importância do modelo de usuário. Por exemplo, um modelo bem feito pode evitar o problema da criação de materiais de documentação linguística que são inúteis para certas populações de falantes. Também pode evitar a criação de materiais de apoio, como dicionários e gramáticas, com características que fazem com que eles sejam abandonados ao chegar às escolas indígenas, pois os seus usuários não sabem como adaptá-los a prática de sala de aula. Obviamente, se queremos criar livros didáticos, uma descrição apropriada do nosso público é uma peça central do projeto.

- Outros dois fatores fundamentais para a preparação de materiais didáticos são as teorias de aprendizado e as metodologias ou abordagens de ensino. É importante ressaltar que não nos importa aqui a natureza das teorias ou abordagens. O que se quer é enfatizar o fato de que os indivíduos que estejam engajados na preparação dos materiais tenham alguma hipótese sobre como esse material vai facilitar o aprendizado desejado. Um dos grandes problemas que vemos nas práticas de ensino de língua em contextos indígenas é a repetição de modelos pedagógicos (alguns meIhores que outros) sem uma maior análise da natureza desses modelos e o seu impacto (positivo ou negativo) na aprendizagem diante dos distintos contextos de uso, objetivos pedagógicos e modelos do usuário. Um exemplo muitas vezes encontrado é o de se sugerir práticas de letramento (i.e., alfabetização) desenvolvidas para populações monolíngues em contextos onde os alunos ou são bilíngues ou (pior) simplesmente não falam a língua alvo. Nesse caso não importa se a metodologia adotada é mais construtivista ou estruturalista pois ela será inequivocamente inapropriada a 
crianças que não falam a língua ${ }^{10}$. Foge ao escopo desse artigo entrar em detalhes sobre as teorias de aprendizagem e as abordagens de ensino existentes para cada tipo de aprendiz ou situação pedagógica. O objetivo é unicamente chamar a atenção do leitor para esses dois elementos e reforçar a necessidade de reflexão explícita sobre esses fatores para se justificar as escolhas feitas quanto as características dos materiais a serem preparados.

- O último elemento é o da descrição linguística e teoria da linguagem. Apesar de parecer óbvia a necessidade de uma descrição linguística para a criação de materiais didáticos, é verdade que existem projetos de ensino de língua (sobretudo de ensino de L2) que por motivos práticos relegam a segundo plano essa descrição e usam abordagens mais funcionalistas (SANTOS GARCIA; CARILLO DE LA CRUZ; VERDIN AMARO, 2016). Podese dizer assim que é possível criar materiais sem um conhecimento mais detalhado das estruturas gramaticais da língua revitalizada. Porém, assim como os demais elementos descritos acima, a falta de um conhecimento a respeito da língua vai seguramente limitar as possibilidades dos autores e pode criar materiais com problemas de ordenação e organização de conteúdo, mesmo que não haja nenhuma menção às estruturas gramaticais ${ }^{11}$. Com relação à teoria da linguagem, é importante sempre lembrar que as teorias de aprendizagem e as abordagens de ensino estão sempre embasadas (explícita ou implicitamente) em teorias sobre a natureza da linguagem. No ensino de língua de forma geral, mesmo em contextos não-indígenas, vemos uma grande confusão entre professores que dizem usar uma teoria ou abordagem e que não entendem a relação (ou a falta de relação) com a maneira como a língua está sendo descrita em seu material. Esse é outro tema que não poderá ser tratado mais detalhadamente neste artigo, mas que precisa ser mencionado.

Muitos autores que trabalham com a revitalização têm enfatizado o papel de novas mídias e tecnologias em seus projetos (BUSZARD-WELCHER, 2001; OBONYO et al. 2011; BALDWIN et al. 2016; GARRETT, 2019). Uma das grandes motivações tem sido a inclusão de falantes jovens neste processo, já que eles tendem a favorecer o uso de tais tecnologias. Outra motivação é a possibilidade de conectar pessoas em diferentes comunidades, cidades, estados e até países através da internet. Uma terceira razão é a de combinar interesses e estratégias de projetos de documentação com projetos de revitalização. Como a internet está cada vez mais onipresente, muitos veem nas ferramentas disponíveis online mecanismos de organização de documentos e arquivos, registros de atividades e projetos, troca de experiências, entre outras atividades. Esta é seguramente uma fronteira da pesquisa com materiais didáticos e paradidáticos que merece ser explorada. Recentemente, vídeos com diferentes tipos de tutoriais, palestras e depoimentos têm tido um crescimento significativo em plataformas como YouTube, Vimeo, etc. Mesmo com todas as restrições que ainda existem no

10 O senso comum está certo ao afirmar que não se alfabetiza em russo uma criança falante de francês, assim como não se alfabetiza em língua indígena uma criança que só fale português. Nesses casos são necessárias uma teoria de aprendizagem e uma abordagem de ensino para a aquisição de segundas línguas. Quando o aprendiz não entende nem frases muito simples e não consegue interagir na língua, a metodologia construtivista não faz sentido. Se ele não conhece nenhum som da língua, o método fônico é uma aberração.

11 Em tom de brincadeira, eu sempre digo que construções locativas como "the book is on the table" não apresentam uma boa estrutura para as primeiras lições de um material de L2 em línguas que tenham sistemas complexos de classificadores nominais. 
Brasil ao acesso a novas tecnologias, os seus usos vêm avançando por pessoas interessadas na revitalização linguística e com certeza essas ferramentas têm muito a contribuir'12.

Em linhas gerais, a pesquisa necessária na área de produção de materiais para revitalização deve levar em conta os seis temas descritos acima. É importante que essa pesquisa seja feita junto com a prática de preparação dos materiais. Também é fundamental ter projetos que possam avaliar o uso desses materiais dentro dos programas de revitalização. Infelizmente, ainda não temos projetos de pesquisa que meçam o impacto de materiais produzidos para línguas indígenas. Contudo, vemos que já existem algumas pesquisas acadêmicas na área de preparação de materiais didáticos para programas de revitalização, como descrito em Amaral et al. (2017). É importante ressaltar o papel inovador que programas de pós-graduação como o da Universidade Federal do Pará (UPFA) têm tido em incentivar esta área com teses e dissertações como Moraes da Silva (2019) e Costa (2020).

\subsection{DOCUMENTAÇÃO PARA A REVITALIZAÇÃO}

A documentação linguística é frequentemente citada como um dos pilares dos programas de revitalização bem sucedidos (AUSTIN; SALLABANK, 2018). A área de documentação linguística já está bastante avançada no Brasil e conta com grupos em instituições de pesquisa espalhadas por todo território nacional (MOORE; GALUCIO, 2016). Infelizmente não podemos dizer que temos suficientes projetos para dar conta de todas as línguas ancestrais do país, mesmo sendo a documentação uma das áreas mais bem estruturadas dentre as mencionadas aqui.

Ao considerar os projetos de documentação linguística através do mundo, Mosel (2012) afirma que a produção de materiais educacionais é raramente integrada aos objetivos explícitos desses projetos. Esse fenômeno causa frequentemente um descompasso entre os objetivos dos pesquisadores e os das comunidades de fala. Como Sallabank (2012) nos lembra, apesar de programas como ELDP enfatizarem que os projetos de documentação devem prever o retorno dos seus produtos para o benefício das comunidades, essas mesmas comunidades estão frequentemente muito mais interessadas na revitalização que na documentação, uma vez que, para muitas, os benefícios diretos da documentação são menos óbvios. Por isso, ela insiste na necessidade dos programas de documentação estarem atentos a temas de planejamento linguístico como os citados na seção 1.2. Austin e Sallabank (2018) apresentam claramente alguns dos pontos mais contenciosos entre programas de documentação e revitalização:

Na visão de vários linguistas da documentação, os materiais para referência e revitalização estariam idealmente baseados em um corpus oriundo da documentação linguística (DL) e seus 


\begin{abstract}
subprodutos. Contudo, a maior parte do material gerado pela DL pode não ser adequado à revitalização, por distintas razões. Primeiramente, esse material contém frequentemente gêneros textuais e tópicos como materiais sagrados, conversas sobre a morte e relações sexuais, além de fofocas, que são inapropriados para aprendizes de língua, especialmente crianças. Segundo, porque os subprodutos da DL tendem a gerar análises linguísticas publicadas em revistas acadêmicas ou gramáticas descritivas escritas em uma língua ocidental usando uma terminologia incompreensível a não-linguistas. Esse material tende a focar em propriedades gramaticais ou fonológicas em detrimento de trechos conversacionais, competência comunicativa ou noções e funções ${ }^{13}$. (p. 210)
\end{abstract}

Os autores também enfatizam outros problemas, como o fato de que um corpus criado para documentação não inclui tradicionalmente exemplos de falas endereçadas a aprendizes (COPE, 2014), uma vez que pesquisadores e informantes tendem a preferir formas mais "puras" ou tradicionais ao invés de documentar a fala de gerações mais jovens, muitas vezes com interferências mais perceptíveis do contato linguístico (DORIAN, 2009). Para Austin e Sallabank (2018) um dos maiores problemas dos projetos tradicionais de documentação é que alguns linguistas da documentação consideram a revitalização como um adendo ("technical add-on", p. 210).

As recomendações de Sungita (2007) e Amery (2009) são um excelente ponto de partida para que os produtos da documentação possam ser usados diretamente no apoio a programas de revitalização. Eles sugerem que haja no corpus exemplos de uso da língua em situações de interação, como conversas cotidianas que façam uso de diferentes funções da linguagem, expressões idiomáticas, além de formas de discurso que ocorram naturalmente e com frequência. Eles também enfatizam a importância de documentar exemplos de interação intergeracional com falantes de diferentes idades. Esses dados são cruciais para se preparar materiais para as gerações mais novas. A inclusão de metadados com objetivos pedagógicos também ajudaria muito a projetos de revitalização que necessitam de materiais didáticos. Nathan e Fang (2009) sugerem que um corpus pode ser muito útil se nele for possível procurar por certos tipos de informação como a (i) linguagem usada em certos tipos de eventos sociais ou culturais relevantes e (ii) certos temas relacionados ao ensino-aprendizagem de línguas (e.g., saudações, números, informação sobre parentesco, etc.).

Muitas vezes quando uma área já está estabelecida e com suas práticas sedimentadas, se torna mais difícil haver modificações significativas nos seus procedimentos. No caso brasileiro, mais que investir em novos projetos de documentação, é importante que os

13 Original em inglês: "In the view of many documentary linguists, materials for reference and revitalization are ideally based on a corpus from language documentation. However, much material in LD corpora and outputs may be unsuitable for revitalization, for several reasons. First, it frequently contains genres or topics such as sacred materials, discussions of death or sexual relationships, as well as gossip, that are inappropriate for language learners, especially children. Second, the outputs of $L D$ tend to consist of linguistic analyses published in academic journals, or descriptive grammars written in a major, typically Western, language, using terminology that is obscure to nonlinguists. They tend to focus on grammatical or phonological features rather than on conversational gambits, communicative competence, or notions and functions". 
pesquisadores comecem a dialogar e participar de iniciativas voltadas à revitalização linguística. É fundamental que estas iniciativas não sejam vistas como subprodutos secundários e que suas necessidades sejam levadas a sério na hora de descrever os projetos, treinar as equipes e estabelecer as listas de produtos exigidas. Nesse sentido, a segunda fase do Projeto de Documentação de Línguas Indígenas do Museu do Índio foi revolucionária (http://gramaticas-prodoclin.blogspot.com/), pois foi além da produção de materiais de documentação que sirvam para a revitalização e propôs como produto final a criação de gramáticas pedagógicas prontas para serem usadas por professores indígenas (SILVA; AMARAL; MAIA, 2014; LIMA, 2020). Essas gramáticas contém um rico material de histórias, diálogos e descrições de situações cotidianas que refletem um uso mais corriqueiro da língua, além de estarem prontas para seu uso pedagógico. O trabalho nas gramáticas também gerou subprodutos de descrição linguística relevantes (e.g., AMARAL, 2018).

É de se esperar que com o avanço da área de revitalização linguística no Brasil, as próprias comunidades comecem a exigir de forma mais clara a criação de produtos semelhantes e que os projetos de documentação sejam mais criativos e inovadores para adaptar as suas técnicas a essas demandas. Também irá acelerar essa transição se projetos de pesquisa em documentação começarem a reportar possíveis experiências que incluam essas novas expectativas e práticas de criação de banco de dados.

\section{ALGUNS EXEMPLOS DE PROGRAMAS DE REVITALIZAÇÃO}

É sem dúvida de vital importância para as iniciativas no Brasil uma revisão dos programas de revitalização que foram desenvolvidos em outras partes do mundo nas últimas décadas. É também necessário estimular mecanismos para facilitar a troca de experiências e documentar as diferentes iniciativas existentes. Esta seção apresenta de forma sucinta alguns casos já consagrados de experiências de revitalização e retomada de línguas ameaçadas. Seria impossível em um único artigo descrever todos estes programas em detalhes. Por isso, esta seção está dividida em tipos de programas, como uma menção a alguns exemplos de programas específicos para cada tipo. Mais que descrever estes programas, o objetivo é instigar o leitor a procurar mais informações sobre os diferentes modelos existentes.

Pérez Báez, Vogel e Patolo (2019) realizaram um dos estudos mais completos sobre programas de revitalização ao redor do mundo. O projeto intitulado Global Survey of Revitalization Effortsfoi financiado pelo instituto Smithsonian dos Estados Unidos e levantou dados sobre 245 esforços de revitalização linguística em cinco continentes com questionários 
traduzidos em sete línguas nacionais ${ }^{14}$. Dentre os muitos dados interessantes apresentados nesse artigo encontramos informações sobre a data de início desses 245 projetos de revitalização linguística. Como já se suspeitava, a grande maioria é bastante recente, sendo que $65,2 \%$ dos projetos de revitalização estudados tiveram início no século XXI. Se contarmos as últimas três décadas, o número se aproxima de $80 \%$. Ou seja, o estabelecimento de programas de revitalização como uma atividade global é recente. Outro ponto importante descrito pelo artigo é o de que existem vários objetivos para se propor um projeto de revitalização, desde objetivos para gerar uma coesão comunitária até objetivos de estudos da língua. Curiosamente, o objetivo mais citado pelos participantes (26,68\%) foi o pedagógico, que inclui desenvolver um currículo de língua, produzir materiais didáticos e inserir as atividades de revitalização dentro do contexto escolar. Ou seja, o ensino da língua é muitas vezes visto não somente como uma maneira para se alcançar um objetivo, mas também como o objetivo a ser alcançado. Quando questionados sobre os tipos de atividades que os projetos de revitalização realizam, as três atividades mais citadas são: a documentação (13.8\%), a preparação de materiais didáticos (12.1\%) e a oferta de cursos de língua (11.1\%). Outra vez, vemos que as atividades de ensino de língua são consideradas importantes pelos participantes desses programas.

Outro dado relevante é o do número de pessoas que se beneficiam desses projetos. Em 62.8\% dos casos os projetos beneficiam um grupo com menos de 100 pessoas. Ou seja, projetos em larga escala para grandes populações são raros. Na verdade, somente $15.6 \%$ dos projetos beneficiam grupos com mais de 1000 pessoas. Além disso, ao contrário do que se possa imaginar, a maioria dos projetos não se resume a beneficiar somente membros que pertençam a comunidade original. $53.1 \%$ dos projetos tem como objetivo beneficiar pessoas de dentro e de fora da comunidade. Com relação à idade, $46 \%$ tem como objetivo trabalhar com crianças, enquanto $54 \%$ são para adultos. Se levamos em conta o grau de proficiência do público, $36 \%$ das atividades visam aprendizes que não falam a língua, 35\% são para pessoas que já tem algum conhecimento da língua e 29\% tem como objetivo apoiar a falantes fluentes. Quando perguntados sobre os resultados alcançados com os programas, 31.1\% disseram que eles não são satisfatórios (ruim ou péssimo), enquanto que $48.3 \%$ classificaram como bons e $20.7 \%$ como excelentes. Reparem que não podemos tomar esses números como uma avaliação formal dos objetivos de cada projeto, eles são simplesmente um reflexo dos sentimentos dos participantes com relação às atividades desenvolvidas.

\footnotetext{
14 Esse artigo é uma leitura obrigatória para todos que queiram conhecer o estado da arte em programas de revitalização. Além dos dados da pesquisa, ele traz uma série de referências bibliográficas importantes. Também recomendo a leitura de Pérez Báez (2016) que traz muitas informações importantes da área.
} 
Talvez um dos dados mais importantes do estudo esteja relacionado às perguntas sobre recursos. $45 \%$ dos participantes dos projetos dizem sentir falta de apoio financeiro, político ou institucional. Alguns citam literalmente a falta de apoio da sociedade civil. Outra área onde os participantes percebem uma real carência é a do apoio pedagógico para as atividades. Muitos reclamam da falta de professores com conhecimento de técnicas de ensino de língua e da necessidade de se ter mais "especialistas em pedagogia de ensino de línguas". Quando questionados sobre o que mais ajudava no desenvolvimento dos projetos, a resposta foi bastante semelhante com a categoria de apoio financeiro, político ou institucional em primeiro lugar (28\% dizem ter esse apoio e o listam como muito importante).

Muitos outros dados e análises são apresentados ao longo do artigo. Para nosso objetivo, é importante ressaltar que a organização da maioria dos programas prevê algum tipo de atividade pedagógica. Como nos lembram Grenoble e Whaley (2006, p. 50), a escolha do tipo de programa de revitalização depende dos objetivos de cada comunidade e dos recursos disponíveis. Vejamos agora alguns modelos adotados por esses programas.

\subsection{PROGRAMAS DE IMERSÃO}

Os programas de imersão têm como princípio básico as teorias que enfatizam o tempo de exposição à língua como fator fundamental do aprendizado. Ou seja, o insumo linguístico (input), de preferência em grandes quantidades, seria crucial para o desenvolvimento da proficiência linguística (HINTON, 2001d). Os programas mais conhecidos focam na aquisição de língua na primeira infância por acreditarem que é mais fácil criar novos falantes das línguas se os aprendizes estiverem no chamado pré-período crítico da aquisição da linguagem (DEKEYSER, 2000). Esses programas normalmente preveem o desenvolvimento de uma infraestrutura na qual os aprendizes convivem com falantes da língua em contextos educacionais estruturados ou semiestruturados, onde a língua a ser aprendida é a única falada. O aprendiz fica assim imerso na língua alvo durante o tempo de instrução. Muitos desses programas combinam o aprendizado da língua com a transmissão de elementos das culturas tradicionais de seus povos. Três dos casos mais conhecidos são os ninhos de línguas Maori (KING, 2001), Havaiano (WARNER, 2001) e Mohawk (JACOBS, 1998). No Brasil temos o exemplo do ninho de língua Kaingang que nasceu de uma parceria com os Maori da Nova Zelândia (NASCIMENTO; MAIA; WHAN, 2017).

Esses programas são muitas vezes vistos como o padrão ouro para a revitalização pois muitos acreditam que é a melhor maneira de se criar novos falantes. Porém, é importante lembrar que os programas de imersão só funcionam quando o tempo de exposição à língua é suficientemente robusto. Ou seja, deve-se criar condições para que os aprendizes passem uma boa parte dos seus dias em um ambiente onde somente a língua revitalizada esteja sendo falada. Logisticamente esses programas apresentam vários desafios. O maior deles é a 
disponibilidade de recursos humanos e financeiros para manter uma estrutura onde haja um grupo de adultos falantes da língua disponível todo o tempo. Eles também exigem a preparação de materiais específicos para as atividades de imersão. Em alguns casos, eles não funcionam em uma estrutura escolar tradicional e por isso são desenvolvidos de forma paralela, apesar do mais comum ser a criação de programas de imersão na idade pré-escolar. É verdade que alguns projetos deram muita evidência a esses programas, como no caso Maori (KING, 2001). Porém, como vimos anteriormente, antes de pensarmos em uma estratégia com esse grau de complexidade é importante garantir que teremos os recursos humanos necessários. Para a maioria das línguas brasileiras, isso significa começar com a formação de falantes adultos (veja a seção 1.2). Um outro problema encontrado com tais programas é a rejeição por parte da comunidade, sobretudo quando focado em aprendizes na primeira infância, pois ao privilegiar a língua revitalizada, as crianças perdem tempo de exposição à língua dominante. Existem também relatos de problemas com agentes governamentais (GRENOBLE; WHALEY, 2006). É preciso ter um plano de ação para que o programa apoie o desenvolvimento dessas crianças quando cheguem à idade escolar e é fundamental explicar aos pais como o programa funciona e porque suas atividades não vão prejudicar seus filhos.

Em geral, nas experiências exitosas através do mundo, vemos que quando um grupo começa um trabalho de revitalização existem algumas etapas a serem concluídas antes da criação de ninhos de língua. Este é sem dúvida um objetivo que todos devem almejar, mas é importante estar consciente da infraestrutura necessária para o sucesso do projeto.

\subsection{PROGRAMAS BILÍNGUES OU DE IMERSÃO PARCIAL}

Os programas bilíngues ou de imersão parcial são modelos utilizados junto à educação formal em escolas onde o tempo de instrução é dividido entre a língua revitalizada e a língua dominante. Alguns dos objetivos básicos desse tipo de programa são o de trabalhar a língua revitalizada sem abandonar a língua dominante, diminuir a rejeição a programas com a língua revitalizada oriunda de programas de imersão total (3.1) e permitir a manutenção por parte dos aprendizes de suas raízes culturais ao se evitar programas inteiramente na língua dominante. Em várias partes da América Latina programas para a educação bilíngue são vistos como o objetivo a ser alcançado, como no caso do México (CASTAÑEDA, 2013) e Peru (ZÚÑIGA; SÁNCHEZ; ZACHARÍAS, 2000). Esses programas recebem constantemente muitas críticas com relação à sua eficiência com relação a processos de revitalização.

É importante ressaltar que as escolas bilíngues onde uma das línguas é minorizada estão em uma situação bastante diferente das escolas bilíngues onde as duas (ou mais) línguas ensinadas são línguas não ameaçadas e oficiais de países com prestígio geopolítico, como no caso de escolas internacionais como a Escola Americana, a Escola Suíço-Brasileira, a Escola Britânica e a Escola Alemã, entre outras. Nessas escolas internacionais não 
é difícil criar uma atitude positiva do processo de aprendizado simultâneo de mais de uma língua que é percebido por pais e alunos como fomentador de um bilinguismo aditivo. Já no caso de línguas minorizadas, pode existir uma percepção equivocada de que o ensino de mais de uma língua prejudica o desenvolvimento da criança (PEARSON, 2008). Além disso, existem dúvidas se a quantidade de insumo (input) em programas bilíngues é suficiente para um verdadeiro processo de aquisição bilíngue em comunidades onde já não há espaços de fala dedicados a língua a ser revitalizada (PEARSON; AMARAL, 2013).

Em geral, o maior problema que encontramos com programas bilíngues na América Latina não está necessariamente relacionado à sua proposta e sim à sua implementação. É um erro pensar que programas bilíngues requerem menos recursos que programas de imersão completa. Na verdade, para serem bem implementados, esses programas requerem mais recursos financeiros, humanos e logísticos. O desenvolvimento de um currículo escolar bilíngue é bastante complexo, com decisões sobre que conteúdo será apresentado em que língua e com qual progressão. A formação do professor também é mais complexa e requer a inclusão de mais áreas e técnicas de ensino. Por fim, a preparação do material também é mais complexa. Em suma, antes de termos programas bilíngues com todos os elementos necessários para funcionar plena e satisfatoriamente, não temos como avaliar concretamente a sua eficácia no contexto latino-americano.

A história recente na América do Norte aponta para algumas limitações dos programas bilíngues. Hinton e Meek (2018) descrevem a história dos programas educacionais para revitalização nos Estados Unidos e Canadá e argumentam que um dos maiores problemas dos programas bilíngues é o fato deles não serem capazes de criar espaços de fala fora da escola. O uso constante do inglês limita o uso da língua indígena. Apesar de um início difícil e de boicotes de financiamento por parte de alguns governos federais (sobretudo durante mandatos de presidentes Republicanos nos Estados Unidos), os programas bilíngues foram melhorando tecnicamente com o passar dos anos. Porém, as comunidades perceberam suas limitações e começaram uma transição para programas de imersão que incluem elementos culturais e a participação direta das famílias e de organizações comunitárias.

Outro ponto para pesquisas futuras diz respeito à relação entre o tipo de programa implementado e os espaços físicos criados para o uso da língua revitalizada. Uma das grandes diferenças entre programas que reforçam o modelo monolíngue na Nova Zelândia e na América do Norte e programas que reforçam a educação bilíngue na América Latina é a de que no caso latino-americano o planejamento foi feito em função da escola (pública) já existente e com a incorporação de novas diretrizes em um modelo educativo estabelecido pelo estado que, no geral, não diferencia espaços de fala distintos para as línguas majoritária e revitalizada. No caso dos países de língua inglesa, talvez por causa da própria força e presença internacional do inglês, os participantes perceberam mais rapidamente que se não criassem espaços físicos para proteger a língua indígena, a 
influência do inglês não permitiria que as línguas revitalizadas fossem usadas. Todos esses fatores só reforçam o que já foi dito anteriormente sobre a necessidade de um planejamento linguístico com o engajamento ativo da comunidade, pois nenhum programa educacional por si só pode resgatar uma língua. 


\subsection{ENSINO DE SEGUNDA LÍNGUA}

Os programas de ensino da língua a ser revitalizada como segunda língua (L2) estão entre as soluções mais simples a serem implementadas. Eles normalmente ocorrem em ambientes de educação formal e usam a estrutura de programas tradicionais de ensino de L2. O tempo de exposição à língua é muito mais limitado que em programas de imersão, por isso requerem menos materiais e recursos humanos. O mesmo professor pode dar aulas para várias turmas. Além de ser um programa mais fácil de ser preparado, ele dificilmente encontra resistências políticas dentro ou fora das comunidades. Muitas vezes é visto como um excelente primeiro passo para se iniciar atividades de revitalização. Outra vantagem desse tipo de programa é que o seu público tende a ser mais velho. Ou seja, é uma das alternativas para preparar falantes adultos para que em seguida sejam capazes de trabaIhar com crianças. É importante ressaltar que esse tipo de programa requer a preparação de recursos específicos. A única vantagem é em termos de quantidade, já que idealmente tanto os materiais e os professores devem seguir estratégias de ensino e aprendizagem que tenham sido testadas e que realmente facilitem o desenvolvimento dos alunos.

As limitações desse tipo de programa são óbvias se comparadas aos dois outros modelos apresentados nas seções 3.1 e 3.2. Com uma menor exposição à língua a ser revitalizada, o aprendiz demora muito mais para desenvolver uma proficiência linguística. Além disso, alunos com diferentes estratégias de aprendizado chegam a resultados diferentes em termos de seu grau de conhecimento e uso da língua. Como em todo programa formal de estudo, vão existir participantes com dedicação, motivação, facilidade e tempo suficientes para aproveitar ao máximo as aulas, enquanto outros podem demorar mais ou até mesmo nunca chegar a um grau de proficiência necessário para usar a língua comunicativamente. Além disso, esse é sem dúvida um dos tipos de programa em que mais pode haver problemas com relação à forma como culturalmente a transmissão de conhecimento é estabelecida dentro da comunidade. Por tentar compensar a limitação do tempo de exposição à língua com práticas que possam facilitar e maximizar a retenção de conteúdo, esses programas acabam usando estratégias de ensino que podem não ser bem compreendidas ou aceitas pelo seu público em comunidades onde a transmissão de conhecimento requer procedimentos que não se adequem a uma limitação temporal ou mesmo espacial. Na América do Norte, existem casos onde programas usaram metodologias externas a comunidade, como o Natural Approach (KRASHEN, 1982), Total Physical Response (ASHER, 1996) ou outras formas de abordagens comunicativas (WESCHE; SKEHAN, 2002) e obtiveram resultados positivos. Em termos de planejamento linguístico é muito importante ter claro o que podemos conseguir (ou não conseguir) com um programa de ensino de segunda língua. Usá-lo como parte de uma estratégia mais ampla para a revitalização pode ser imprescindível, mas achar que um curso de L2 pode reverter um processo de perda linguística não é realista. 


\subsection{PROGRAMA MESTRE-APRENDIZ}

O programa mestre-aprendiz foi criado para responder a uma situação específica no contexto de perda linguística de certas populações do oeste americano (HINTON, 2001c). Como vimos anteriormente, um dos requisitos iniciais para um programa de revitalização é o de se identificar uma potencial comunidade de fala. Contudo, existem algumas línguas da América do Norte que já não contam com essa comunidade, seja porque não há mais membros vivendo em reservas indígenas, ou porque essas comunidades não têm condições de levar a cabo um projeto de resgate linguístico no momento. Em um caso como esse, a solução foi encontrar indivíduos mais jovens que servissem de "guardiões da língua". O objetivo inicial do programa foi o de passar o conhecimento linguístico de um falante (normalmente mais velho) para um não-falante (normalmente mais jovem), criando duplas de trabalho onde os participantes interagem e aprendem a língua de forma natural. A expectativa é de que ao manter a língua viva com alguns falantes será possível reverter o processo de perda no futuro, quando existam as condições para tal.

O programa se baseia em metodologias de imersão, por isso o uso de outras línguas que não sejam a língua alvo é completamente proibido durante as atividades. O aprendiz e o mestre decidem juntos quais são os contextos de uso da fala que serão usados. Incentivase que o aprendizado se dê em situações comunicativas do cotidiano, como cozinhar, jardinar, lavar roupa, fazer caminhadas, fazer artesanato, etc. A transmissão de conhecimento é feita sobretudo na modalidade oral, a escrita é desencorajada. A ideia é a de que a interação verbal e não-verbal durante as atividades seja suficiente para a transmissão de todos os conhecimentos necessários para o aprendiz. Existe um período de treinamento das duplas, onde ambos aprendem sobre as bases dos programas de imersão e depois as atividades são feitas sem supervisão. No caso californiano, cada membro da equipe recebeu uma ajuda de custo de US $\$ 3000$ por 360 horas de imersão. O objetivo era de que ao final de três anos os aprendizes se tornassem fluentes na língua, obviamente sem uma expectativa de que sua fluência fosse semelhante à do mestre. De forma geral, os resultados foram positivos, com algumas duplas tendo avançado mais que outras. Alguns desafios do programa foram o de manter o envolvimento dos participantes após o período inicial, encontrar mestres fluentes em áreas de interesse que fossem atrativas para os aprendizes e a dificuldade dos aprendizes em praticar a língua fora do contexto do programa, pela falta da comunidade de fala.

Hinton et al. (2018a) citam outros contextos de uso para um programa dessa natureza ao descreverem a experiência de um programa semelhante implementado no Canadá a partir de 2008 pelo First Peoples' Cultural Council (Conselho Cultural das Primeiras Nações). Em contextos onde existe uma quebra de transmissão intergeracional entre velhos e adultos, um programa como mestre-aprendiz pode ajudar na formação de pessoal mais 
jovem para atuar em ações educacionais de revitalização junto a crianças e jovens. O programa canadense também trouxe outras inovações. Existem alguns módulos mais formalizados de 50 horas de imersão cada. Os aprendizes para continuar no programa têm que passar por processos de avaliação do seu progresso por outros membros da comunidade que falam a língua, além do seu mestre. Os workshops e sessões de treinamento dos participantes são mais frequentes. É importante notar que o incentivo financeiro tanto para mestres como para aprendizes continua existindo.

Além dos programas da Califórnia e do Canadá, existem outros programas semelhantes nos Estados Unidos e na Austrália. A implementação de um programa do tipo mestreaprendiz no Brasil poderia ser de grande valia em alguns casos. Porém, como as experiências internacionais demonstram, esse programa tem que fazer parte de uma estratégia mais ampla de revitalização para que os seus resultados possam verdadeiramente apoiar práticas comunitárias que levem ao uso da língua por um grupo maior de indivíduos.

\subsection{PRÁTICAS COMUNITÁRIAS E FAMILIARES}

Uma das maiores restrições dos modelos apresentados até aqui é que eles são baseados em atividades de transmissão da língua que acontecem em ambientes especificamente preparados para este fim. Ninhos de língua, escolas, cursos comunitários, encontros de mestres com aprendizes são todas excelentes ferramentas para diferentes estratégias de revitalização, porém não respondem diretamente a uma necessidade básica, que é a criação de espaços (não educacionais) para o uso da língua, incluindo um dos mais importantes: o ambiente familiar. Um dos pilares do programa Mohawk foi justamente o de incentivar os pais e avós a voltar a falar a língua dentro de casa e reforçar a transmissão intergeracional familiar (PETERS; PETERS, 2013).

É importante notar que as estratégias de revitalização que envolvem as comunidades e as famílias não são substitutos para os programas descritos anteriormente. Apesar de estarem baseadas em técnicas específicas, elas são na verdade peças centrais do planejamento linguístico para o sucesso dos projetos de revitalização. Um excelente exemplo desta conjugação de abordagens e programas é o caso Maori na Nova Zelândia. Os Maori ficaram conhecidos por terem construído um dos mais famosos programas de ninhos de língua, porém, seu plano de revitalização envolve muitas outras estratégias, dentre elas o projeto Katahi Mano Kaija, Katahi Mano Wawata ("Mil Lares, Mil Sonhos"), descrito em O’Regan (2018), cujo objetivo é de levar a língua para dentro de 1000 casas até 2025. Em seu capítulo, a autora conta os desafios enfrentados por sua comunidade no processo de revitalizar a língua e como que a inclusão das famílias com o objetivo de levar a língua para dentro das casas foi um divisor de águas e possibilitou um avanço significativo do projeto. Um dos pontos que deve ser destacado é o da importância do planejamento 
linguístico a nível familiar. Junto com as atividades comunitárias desenvolvidas para promover a língua, o planejamento familiar deu os subsídios necessários para que as famílias recebessem o apoio logístico para estabelecer seus objetivos individuais e organizar suas ações de transmissão linguística.

Uma outra ideia interessante de ação comunitária é apresentada por Zahir (2018), que descreve um "ninho de língua para a língua". A sua observação vem de décadas trabalhando com o ensino de Lushootseed, uma língua da família Salish falada na costa oeste dos Estados Unidos e Canadá e severamente ameaçada. Depois de trabalhar com o ensino da língua para adultos usando metodologias de segunda língua, ele percebeu, ao examinar os contextos de revitalização de línguas ameaçadas, que "o aprendizado (de uma língua) não leva ao seu uso se não existirem situações que imponham a necessidade de falar a língua” (p. 157). Ele então propôs criar um "ninho" para a língua. Como vimos anteriormente, os ninhos de língua são programas de imersão para crianças na primeira infância para que possam adquirir a língua desde cedo. O "ninho" proposto por Zahir não é para o desenvolvimento das crianças, mas para nutrir o uso da língua por qualquer pessoa, criando espaços de fala. São lugares geograficamente determinados dentro das comunidades onde o uso do inglês é proibido e todos devem trabalhar para "alimentar" a língua indígena. Como uma planta que precisa ser regada e protegida quando ainda é muito pequena, algumas línguas ameaçadas precisam desse cuidado para crescerem mais fortes e sobreviverem por conta própria, daí a necessidade de um "ninho para a língua". Ele também lista uma série de situações comunicativas que são aos poucos incorporadas às práticas cotidianas, aumentando o uso língua revitalizada na prática diária da comunidade. Em seu texto, ele apresenta algumas ideias, sugestões e uma metodologia para as comunidades darem início ao "ninho de língua para a língua".

Existem vários outros exemplos de projetos de revitalização que utilizam ações comunitárias ou que envolvem diretamente a transmissão da língua em ambiente familiar. Essas ações podem estar ligadas a práticas culturais relevantes para seus respectivos povos. Alguns grupos de Papua Nova Guiné usavam a língua ao aprenderem as suas danças tradicionais (HARRIS, 1977). No Havaí, Baker (2018) descreve um projeto onde histórias tradicionais foram adaptadas para o teatro e encenadas na língua havaiana, com uma recepção excepcional do público em várias cidades do estado americano. Os programas de base comunitária têm uma vantagem adicional, pois podem incorporar mais naturalmente mecanismos de transmissão de conhecimento que sejam mais compatíveis com as práticas culturais vigentes.

\subsection{MODELOS DE RETOMADA DE LÍNGUAS ADORMECIDAS}

Existem vários termos usados para descrever o processo de resgate de uma língua que já não é mais falada. Além da palavra "resgate", muitos usam termos como "retomada", 
"ressurgimento", "despertar" e até "ressuscitar", apesar desse último ter uma conotação negativa, por sugerir que a língua estava morta, e por isso tem sido abandonado recentemente. Usarei a palavra "retomada" para descrever essa situação, sem fazer uma distinção teórica clara entre os vários termos, mas simplesmente me referindo ao estágio da língua quando se dá início o processo de revitalização, ou seja, casos onde não há mais falantes vivos.

O resgate linguístico é sem dúvida um dos cenários mais difíceis para uma comunidade que queira voltar a falar a língua de seus ancestrais. O primeiro requisito central e fundamental para que tal projeto possa ser levado a cabo é a existência prévia de uma documentação extensa. Na seção 1.5 vimos algumas características de uma documentação ideal para processos de revitalização. Porém, mesmo que não tenhamos uma documentação ideal, como a descrita acima, ainda assim é possível levar a frente um projeto dessa natureza, desde que tenhamos o suficiente. Para alguns autores, como Amery (2000), essa documentação deve ter não somente uma lista de palavras, mas também textos e descrições gramaticais. Para ele, não podemos chamar de retomada um processo com uma língua da qual só tenhamos acesso a uma lista descontextualizada de palavras, já que elementos centrais da língua terão sido perdidos.

Talvez o elemento mais importante para determinar o que seria suficiente para um processo de retomada sejam os objetivos da comunidade de fala. Grenoble e Whaley (2006) enfatizam que é fundamental ter expectativas realistas quanto ao que se quer alcançar com o trabalho de retomada. Na seção "Definições e considerações”, vimos uma breve discussão sobre os diferentes objetivos de projetos de revitalização, enfatizando que não devemos insistir no "ou tudo ou nada", ou seja, ou voltamos a falar a língua com os mesmos usos, frequência e fluência que nossos ancestrais, ou simplesmente não a revitalizamos. Para projetos de retomada, é crucial que esses objetivos sejam alcançáveis e as expectativas sejam realistas.

Em todos os casos, é necessário um processo, muitas vezes longo e complexo, de adaptação do léxico, estruturas fonológicas e muitas vezes morfossintáticas. Não se deve subestimar o tempo, a dedicação e os recursos necessários para esta etapa do planejamento do corpus, antes mesmo de se pensar no planejamento do status e o planejamento da aquisição (ver seção 1.2). Como, ao princípio do processo, a língua a ser retomada não tem nenhuma função sociocomunicativa, o planejamento do status também pode ser bastante complexo e seguramente terá um impacto nas expectativas e objetivos. Por fim, o planejamento da aquisição terá que levar em conta a formação linguística e técnica dos adultos que serão responsáveis pelas atividades junto às gerações mais jovens. Como não há falantes mais velhos, modelos como mestre-aprendiz não são possíveis para desenvolver a competência comunicativa de adultos. Também não é possível criar programas de imersão clássicos. 
Apesar de todas as dificuldades, existem alguns exemplos de retomada de línguas indígenas com sucesso ${ }^{15}$. Na seção 1.2. vimos o caso Wampanog, onde o trabalho intenso de jessie little doe baird levou ao despertar da língua de seus ancestrais e onde a comunidade apoiou e se apropriou do projeto a ponto de construir várias etapas de planejamento linguístico e de implementação das atividades de ensino, aprendizado e uso. Um outro caso, onde podemos dizer que houve um sucesso dos objetivos propostos, é o caso dos Kaurna, na Austrália. Amery $(2016,2017)$ relata o processo de resgate dessa língua que já não contava com falantes e que através de uma colaboração entre linguistas e membros da comunidade conseguiu ser resgatada. Em seus textos, ele descreve o processo de planejamento linguístico e as limitações impostas pelos documentos existentes. Ele afirma que o objetivo não é que o Kaurna substitua o inglês, mas que a língua possa ser um instrumento importante da cultura e identidade do povo.

Essas experiências nos mostram que apesar de ser muito difícil usar a estrutura de programas de ensino formal de língua em um primeiro momento em processos de retomada, algumas práticas de programas de base comunitária são não somente possíveis, como comumente adotadas. No caso da língua Abenaki-Penobscot do Leste (Maine, Estados Unidos), mesmo não havendo nenhum falante nativo vivo dessa língua, a comunidade organizou um material de documentação para servir de base para a sua revitalização, e o usa em atividades comunitárias onde o vocabulário da língua é empregado para realizar tarefas.

No Brasil, temos o caso de retomada da língua Pataxó descrita em Bomfim (2017). O processo que começou em 1998 com um grupo de professores e pesquisadores das próprias comunidades tem conseguido organizar o léxico e a ortografia de uma língua que já não é falada há muitas décadas e que conta com pouquíssima documentação formal. Entre os elementos mais interessantes do projeto estão seus objetivos de valorização de práticas comunitárias com conteúdo linguístico, o envolvimento de jovens no processo de resgate, o estímulo a participação de famílias para transmissão linguística, além da a criação de cantos e de materiais de ensino. O processo de planejamento linguístico reforça práticas tradicionais de negociação de ações comunitárias com aprovação das lideranças. A autora não indica em seu texto o quanto se avançou para alcançar o objetivo descrito de que "em dez ou vinte anos, no máximo, a fluência na língua antiga pudesse ser retomada” (p. 321), porém é importante ressaltar que os maiores frutos de um processo de revitalização dessa natureza (e com esse grau de dificuldade) não estão necessariamente em medidas de grau de fluência, mas no impacto que as atividades desenvolvidas possam ter no fortalecimento das populações locais, no seu bem-estar, no engajamento com a sua cultura ancestral e na sua capacidade de colaboração para defender seus interesses e a sua sobrevivência. 


\section{A REVITALIZAÇÃO LINGUÍSTICA NO BRASIL}

Se levarmos em conta todas os estudos e práticas citados até aqui, vemos que ainda nos resta muito trabalho pela frente para estabelecer uma área de pesquisa e atuação em revitalização linguística no Brasil. Como mencionado na introdução, o objetivo deste texto é o de incentivar o debate acadêmico e sugerir pontos de discussão para que possamos pouco a pouco construir uma estrutura dentro da academia de apoio às comunidades interessadas em revitalizar suas línguas. Para isso, nesta seção, vemos alguns desafios encontrados no Brasil para avançarmos com uma área de estudos em revitalização linguística, em seguida apresento algumas sugestões a serem debatidas sobre como organizar os estudos em revitalização com uma tentativa de definir algumas áreas de pesquisa e trocas de experiência.

\subsection{OS DESAFIOS NO BRASIL}

Os desafios que encontramos no Brasil são de diferentes naturezas. Em alguns casos, estão mais relacionados a variáveis externas e em outros a variáveis internas. Do ponto de vista da comunidade acadêmica, se conseguirmos criar estruturas de apoio dentro das instituições, poderemos talvez minimizar o impacto dos desafios externos e seguramente poderemos apoiar os membros das comunidades de fala de forma mais eficiente.

Sabemos que existem muitos desafios estruturais, sobretudo na atual conjuntura política, onde prevalece um discurso oficial de negação à diversidade e à existência de minorias. Em toda a história recente da República, conseguir o apoio constante de instituições governamentais sempre foi uma tarefa árdua. Reparem no uso da palavra "constante", uma vez que apoios esporádicos para certos projetos e ações ou políticas desconectadas e infrequentes não são suficientes para criar um efeito duradouro que possa reverter a perda linguística, fruto de séculos de perseguições e ataques. Se o exemplo Maori nos ensina algo é que necessitamos de grupos de trabalho permanentes para alcançar resultados significativos. Infelizmente o cenário atual no Brasil é pior do que o da falta de apoio oficial, pois ele reflete um cenário de boicote direto, com a tentativa de eliminação dos povos, culturas e línguas. Assim, toda ação é necessariamente um ato de resistência semelhante ao vivido pelas populações indígenas antes do reconhecimento legal de seus direitos com a Constituição de 1988.

O retrocesso no apoio estrutural a nível governamental também é acompanhado de um certo retrocesso de apoio cultural da população não-indígena. Um dos grandes desafios no Brasil sempre foi o de se educar a maioria do país para a importância de se proteger o patrimônio de povos, culturas e línguas ancestrais em todo território nacional. O discurso do ódio cultural também ganhou força nos últimos anos, porém aqui vemos uma oportunidade única. Diferentemente de outros momentos históricos em que 
esse discurso levou a práticas de genocídio cultural, hoje em dia os povos indígenas estão mais organizados para defender seus interesses. O que do ponto de vista da revitalização é altamente positivo, pois as práticas de manutenção e resgate linguístico são mais facilmente vistas como práticas de resistência, o que leva a menor rejeição a criação de programas de língua nas comunidades.

Apesar de central e muito importante, não faz parte dos objetivos deste texto discutir a fundo os temas políticos, econômicos, territoriais ou históricos que afetam a perda linguística. Por isso, talvez a área mais relevante para nossa discussão seja a dos desafios acadêmicos. Para os que estão dentro da academia, não é difícil constatar como o discurso de vanguarda é constantemente contrastado com uma prática extremamente conservadora. Normalmente se usa o argumento da "qualidade" para se justificar a reprodução de modelos acadêmicos já consagrados. Talvez a instância onde esse conservadorismo esteja mais visível seja na pós-graduação. A dificuldade de formar novos quadros com a qualidade acadêmica desejada leva muitas vezes à reprodução de práticas que dificultam a inovação por parte dos projetos de pesquisa propostos. É verdade que vários programas no Brasil já buscam soluções para esse problema e que muitas delas têm levado a práticas importantes de inclusão de minorias e de apoio a projetos de pesquisa em temas "não-tradicionais". Para que a revitalização avance, temos que aperfeiçoar essas práticas. Também temos que rever certas caraterísticas e objetivos de projetos existentes, como por exemplo, os projetos de documentação e descrição de línguas ameaçadas. Como vimos na seção 1.5, não basta seguir os padrões estabelecidos por programas internacionais e esperar que o que se está documentando sirva para a revitalização. Temos que expandir as práticas existentes para essa realidade.

Por último, é necessário estruturar academicamente o trabalho em revitalização para estarmos prontos para responder às diferentes demandas de possíveis parceiros das comunidades de fala. Como já vimos, a revitalização começa e termina na comunidade de fala, mas as instituições de pesquisa têm o dever de estar prontas para apoiar essas práticas. $\mathrm{Na}$ próxima seção (3.2) veremos algumas sugestões para avançarmos nesta direção.

\subsection{ALGUMAS ÁREAS DE ESPECIALIZAÇÃO}

Como mencionado na introdução, durante o primeiro Viva Língua Viva, vários professores, pesquisadores e ativistas discutiram temas de relevância para a revitalização linguística no Brasil e apresentaram ideias de como fazer a área avançar dentro e fora da academia. Uma das questões a serem debatidas é como organizar o conhecimento acadêmico visando apoiar esta empreitada. Com base no que vimos nas seções 2 e 3, apresento algumas ideias para iniciarmos um debate sobre a estrutura da área de revitalização linguística e alguns temas que possam ser abordados por mesas redondas, painéis e até sessões específicas durante o próximo encontro do Viva Língua Viva. 
Como vimos, a revitalização é um campo multidisciplinar por natureza, assim esperase um diálogo intenso com antropólogos, educadores, historiadores, cientistas políticos, psicólogos e porque não arquitetos, agrônomos, engenheiros, e todos os profissionais nos mais diversos campos de atuação que possam apoiar projetos que levem a manutenção cultural e linguística das populações indígenas brasileiras. Ao mesmo tempo que ampliamos o diálogo, temos sempre que nos lembrar que quando falamos de revitalização linguística temos um objetivo muito claro com os resultados do trabalho. Esses objetivos podem estar totalmente sincronizados com os de outras áreas, como por exemplo a educação, a descrição linguística e a documentação, ou podem às vezes se distanciar. Em alguns casos, para se obter melhores resultados na revitalização de uma língua pode ser necessário desvencilhar nossos projetos de contextos educacionais formais, retirando inclusive as atividades da escola ${ }^{16}$. Por isso, é importante ter claro os objetivos de cada área de atuação.

É de fundamental importância promover as discussões sobre o planejamento linguístico. Aqui vale ressaltar as diversas etapas e elementos envolvidos no planejamento. Com base na divisão apresentada por McCarty (2018), vista na seção 1.2, é necessário aprofundar os estudos nas três etapas de planejamento de status, corpus e aquisição. É verdade que os linguistas têm contribuído para o planejamento de corpus de forma significativa, mas isso não significa que também não possam contribuir com as duas outras áreas, ou pelo menos entender suas necessidades para melhor apoiar o trabalho como um todo. Esta discussão deve necessariamente envolver pelo menos educadores e antropólogos. Ao discutirmos o planejamento linguístico, é mais fácil incluir análises sobre como áreas afins podem ajudar na manutenção linguística, como por exemplo a produção artística e os estudos culturais ${ }^{17}$.

A segunda área de fundamental importância é a do desenvolvimento e avaliação de programas de língua. Essa é uma área complexa que requer a inclusão de diferentes disciplinas, da linguística aplicada à educação indígena, linguística descritiva, psicolinguística, etc. É preciso que comecemos a pensar na área de avaliação de programas e mecanismos que possam descrever seus impactos. Estes estudos têm que incluir a pesquisa sobre modelos de revitalização já desenvolvidos dentro e fora do Brasil (como os descritos na seção 2). Também podemos incluir aqui a produção, o uso e a avaliação de materiais didáticos para fins de revitalização. Da linguística aplicada devemos incorporar os estudos sobre métodos, abordagens e as discussões sobre o papel facilitador que o professor e as metodologias podem ter no processo de aprendizagem. Muito deve ser feito nessa área e seria excelente que o Viva Língua Viva servisse de vitrine para a troca de experiências por diferentes grupos, além de discussões sobre como fazer a ponte entre o ensino de língua em contextos indígenas e não-indígenas.

16 Não estou advogando pela separação dos projetos de revitalização dos programas de educação indígena. Simplesmente aponto uma opção que pode ser relevante dependendo do contexto onde as atividades ocorram.

17 Seria interessante pensar como projetos como Cineastas Indígenas poderiam ser usados com funções específicas em programas de revitalização. 
Uma terceira área com um papel central nos processos de revitalização é o da descrição e documentação linguística. No contexto brasileiro atual é fundamental darmos prosseguimento às discussões sobre como a documentação linguística pode apoiar de forma consciente e eficaz os projetos de revitalização linguística, como vistos na seção 1.5. Por motivos semelhantes, também devemos incluir nessa área a descrição linguística, uma vez que, assim como a documentação, ela tem sido pautada por necessidades acadêmicas e tem colocado em segundo plano seu impacto na revitalização. A pergunta básica continua sendo: como podemos descrever e documentar as línguas de forma a responder à demanda dos objetivos das comunidades de fala?

A quarta área diz respeito às possíveis contribuições dos estudos em cognição e aprendizado para os projetos de revitalização. Esses estudos estão muitas vezes divididos em áreas como teorias do aprendizado, psicolinguística e aquisição de língua. Essas disciplinas têm seus próprios objetivos de pesquisa, alguns deles coincidem com os objetivos da revitalização e outros não. Por isso é importante articular uma colaboração mais estreita onde os diversos pesquisadores possam estar cientes das necessidades práticas para a aplicação de seus conhecimentos em contextos de revitalização.

Uma quinta área fundamental é o de estudos antropológicos sobre as comunidades de fala, principalmente os que focam em práticas de organização e transmissão de conhecimentos. Quanto mais dados tenhamos sobre o aprendizado em contextos indígenas tradicionais, mais será possível desenvolver programas de revitalização que reflitam as práticas adotadas pelas comunidades para que as ações propostas se integrem melhor ao contexto de uso da língua a ser revitalizada. Aqui também é possível incluir discussões sobre políticas linguísticas e variáveis que tenham levado à perda linguística.

Essas são apenas algumas ideias de áreas a serem consideradas em uma discussão acadêmica sobre a revitalização de línguas. Existem muitas outras áreas que podem contribuir de forma significativa para o debate, como: estudos históricos sobre a perda linguística, estudos culturais e diaspóricos, pesquisas de cunho sociolinguístico com línguas minorizadas, contribuições de disciplinas da área médica e de saúde mental, estudos nas áreas de geografia, ciências políticas, geologia, agronomia, engenharia florestal, etc. Se mantivermos o foco na questão da sobrevivência das línguas ameaçadas, não existe a princípio uma restrição às áreas a serem incluídas.

\section{CONCLUSÃO}

A proclamação da Assembleia Geral das Nações Unidas que estabelece a Década Internacional das Línguas Indígenas entre 2022 e 2032 é o reconhecimento de que a luta pela preservação das línguas ancestrais através do mundo é mais que uma preocupação 
linguística. Organismos internacionais como a UNESCO há muito reconhecem que a língua é a expressão mais íntima, forte e contundente de um povo, sua cultura e tradições, e que a manutenção de uma língua está diretamente relacionada à saúde e à prosperidade das populações minorizadas. É chegada a hora de um envolvimento maior das instituições acadêmicas na luta pela preservação do nosso patrimônio linguístico. No Brasil, eventos como - Viva Língua Viva vieram para ficar e cabe aos seus participantes discutir e propor pesquisas e ações de apoio a preservação e revitalização das línguas ameaçadas.

Este artigo visa contribuir com esse esforço apresentando algumas áreas de conhecimento e atuação que compõem o campo da revitalização linguística na literatura internacional. Uma das virtudes deste texto também é uma de suas grandes falhas. Ao tentar coletar, resumir e apresentar para um público falante de português alguns dos trabalhos centrais da área escritos em inglês, o texto não alcança a amplitude necessária dos trabalhos já em andamento em território nacional. Por isso, é importante que, como comunidade acadêmica, tenhamos esforços nessa direção. As considerações apresentadas na seção 2 têm como objetivo iniciar uma discussão sobre como organizar nossos esforços acadêmicos para impulsionar uma disciplina voltada para a revitalização de línguas. Seguramente, no próximo Viva Língua Viva poderemos avançar ainda mais na construção do campo, aproximando cada vez mais o trabalho acadêmico das demandas de professores, ativistas e defensores das línguas indígenas e das suas comunidades de fala. Como afirmam Hinton, Huss e Roche (2018), na introdução de uma das mais recentes compilações de textos sobre o tema:

\footnotetext{
Como uma reação a uma história de opressão e de assimilação forçada, os movimentos de revitalização linguística são vistos pelas comunidades de fala como um caminho para a cura, a justiça e o empoderamento. A revitalização de uma língua é geralmente parte de um renascimento étnico muito mais amplo. A revitalização se relaciona, influencia e é influenciada pela recuperação de tradições culturais, o reaprendizado de protocolos comportamentais e das maneiras de se relacionar com a família, amigos e membros da comunidade, readquirindo uma relação com a terra, lugares, plantas e animais, e reestabelecendo mecanismos de se relacionar com eles. A revitalização linguística se transformou em um movimento mundial, unindo esforços de pessoas que trabalham em prol de milhares de línguas ameaçadas (HINTON; HUSS; ROCHE, 2018, p. xxii). ${ }^{18}$
}

18 "As a reaction to a history of oppression and forced assimilation, language revitalization movements are seen by the speech communities as paths to healing, justice, and empowerment. Revitalization of a language is generally part of a much broader ethnic revival. It relates to, informs, and is informed by the revival of cultural traditions, the relearning of behavioral protocols, and ways of relating to family, friends, and community members, regaining a relationship to the land and to places, plants, and animals, and reviving ways of relating to them. Language revitalization has become a worldwide movement, engaging the efforts of people working for the benefit of thousands of endangered or threatened languages." 


\section{REFERÊNCIAS}

AMARAL, L. A Framework for Designing Pedagogical Materials in Indigenous Languages: Examples from Brazil and Mexico. Revista Tellus, no prelo.

AMARAL, L. Describing Wapichana asymmetric negation. In: HOLLE- BRANDSE, B. et al. (eds.). Thoughts on Mind and Grammar: A festschrift in honor of Tom Roeper. Amherst-MA: University of Massachusetts, 2018. v. 41, p. 1-14.

AMARAL, L. et al. Diálogos entre a linguística, a educação e a antropologia na produção de materiais de alfabetização na língua Sanöma. Revista LinguíStica, v. 13, n. 1, p. 104-125, 2017.

AMARAL, L. Bilinguismo, aquisição e letramento e o ensino de múltiplas línguas em escolas indígenas no Brasil. Cadernos de Educação Escolar Indígena, v. 9, n. 1, p. 12-32, 2011.

AMARAL, L.; MEURERS, D. Conceptualizing student models for ICALL. In: CONATI, C.; McCoy, K. (ed.). User Modeling 2007: Proceedings of the Eleventh International Conference. Wien, New York, Berlin: Springer, 2007, (Lecture Notes in Computer Science).

AMERY, R. Warrabarna Kaurna! Reclaiming an Australian language. Lisse: Swets and Zeitlinger, 2000.

AMERY, R. Phoenix or relic? Documentation of languages with revitalization in mind. Language Documentation and Conservation, v. 3, n. 2, p. 138-148, 2009.

AMERY, R. Warraparna Kaurna: Reclaiming an Australian language. Adelaide: University of Adelaide Press, 2016.

AMERY, R. Kaurna reclamation and re-introduction. Revista LinguíStica, v. 13, n. 1, p. 262-280, 2017.

ARRUTI, J. M.; VIEIRA, J. C.; SILVA, S. R. da. Território, educação e língua: notas sobre a afirmação étnica Munduruku no Baixo Tapajó. Revista Ciências da Sociedade, v. 3, n. 5, p. 118-139, 2019.

ASHER, J. Learning Another Language Through Actions. 5th. ed. Los Gatos, CA: Sky Oaks Productions, 1996.

AUSTIN, P.; SALLABANK, J. Language documentation and language revitalization: Some methodological considerations. In: HINTON, L.; HUSS, L. M.; ROCHE, G. (ed.). The Routledge handbook of language revitalization. New York and London: Routledge, 2018. cap. 20, p. 207-215.

BAKER, C. M. K. Hawaiian medium theatre and the language revitalization movement. In: HINTON, L.; HUSS, L. M.; ROCHE, G. (ed.). The Routledge handbook of language revitalization. New York and London: Routledge, 2018. cap. 22, p. 227-235.

BALDWIN, D.; COSTA, D.; TROY, D. Myaamiaataweenki eekincikoonih- kiinki eeyoonkiaapisaataweenk: A Miami language digital tool for language reclamation. Language Documentation \& Conservation, v. 10, p. 394410, 2016

BOMFIM, A. B. Patxohã: A retomada da língua do povo Pataxó. Revista LinguíStica, v. 13, n. 1, p. 303-327, 2017.

BRAGGIO, S. L. B. Políticas e direitos linguísticos dos povos indígenas brasileiros. Signótica, v. 14, p. 129-146, 2002.

BUSZARD-WELCHER, L. Can the web save my language? In: HINTON, L.; HALE, K. (ed.). The Green Book of Language Revitalization in Practice. Leiden: BRILL, 2001. cap. 26, p. 331-345.

CASTAÑEDA, E. R. La educación indígena em México. México: Universidad Nacional Autónoma de México, 2013.

COPE, L. Applied linguists needed: Cross-disciplinary networking in endangered language contexts. Abingdon: Routledge, 2014.

COSTA, C. D. N. da. Proposta de Material Didático para a Língua Sakurabiat. Dissertação (Mestrado) Universidade Federal do Pará, Belém-PA, 2020. 
CZAYKOWSKA-HIGGINS, E. Research models, community arrangement, and linguistic fieldwork: Reflections on working within Canadian indigenous communities. Language Documentation and Conservation, v. 3, n. 1, p. $15-50,2009$

D’ANGELIS, W. da R. Línguas indígenas no Brasil: urgência de ações para que sobrevivam. In: BOMFIM, A. B.; COSTA, F. V. F. da (ed.). Revitalização de língua indígena e educação escolar indígena inclusiva. Salvador, Brasil: EGBA, 2014. p. 93-118.

DEKEYSER, R. The robustness of critical period effects in second language acquisition. Studies in Second Language Acquisition, v. 22, n. 4, p. 499-533, 2000.

DIAS DE PAULA, E.; TAPIRAPE', J. X. Revitalização de línguas indígenas no Brasil: o caso dos Apyãwa. Revista LinguíStica, v. 13, n. 1, p. 215-230, 2017.

DOBRIN, L. From linguistic elicitation to eliciting the linguist: Lessons in community empowerment from Melanesia. Language, v. 84, n. 2, p. 300-324, 2008.

DORIAN, N. C. Age and speaker skills in receding languages: How far do community evaluations and linguists' evaluations agree? International Journal of the Sociology of Language, v. 200, p. 11-25, 2009.

DWYER, A. M. Ethics and practicalities of cooperative fieldwork and analysis. In: GIPPERT, J.; HIMMELMANN, N. P.; MOSEL, U. (ed.). Essentials of language documentation. Berlin: Mouton de Gruyter, 2006. p. 33-66.

DWYER, A. M. Models of successful collaboration. In: GRENOBLE, L.; N. LOUANNA FURBEE (ed.). Language Documentation Practice and Valves. Amsterdam, The Netherlands: John Benjamins Publishing Co., 2010. p. $193-212$.

FERREIRA, M. K. L. A educação escolar indígena: um diagnóstico crítico da situação no Brasil. In: SILVA, A. L.; FERREIRA, M. K. L. (ed.). Antropologia, história e educação: a questão indígena e a escola. São Paulo - Brasil: Global, 2001. p. 71-111

FISHMAN, J. A. Reversing Language Shift: Theoretical and Empirical Foundations of Assistance to Threatened Languages. Clevedon, UK: Multilingual Matters, 1991.

FRANCHETTO, B., GODOY, G. Primeiros passos da revitalização da língua Guató: uma etnografia. Revista LinguíStica, v.13, n.1, p. 281-302, 2017

FREIRE, J. R. B. A demarcação das línguas indígenas no Brasil. In: CUNHA, M. C.; CESARINO, P. N. (ed.). Políticas culturais e povos indígenas. São Paulo - Brasil: Cultural Acadêmica, 2014. p. $287-312$.

GARRETT, A. Online dictionaries for language revitalization. In: HINTON, L.; HUSS, L. M.; ROCHE, G. (ed.). The Routledge handbook of language revitalization. New York and London: Routledge, 2018. cap. 19, p. $197-206$.

GRENOBLE, L.; WHALEY, L. (ed.). Endangered languages: Current issues and future prospects. Cambridge: Cambridge University Press, 1998.

GRENOBLE, L.; WHALEY, L. Saving Languages: An introduction to language revitalization. Cambridge: Cambridge University Press, 2006.

HARRIS, S. Milingimbi Aboriginal learning contexts. Tese (Doutorado) - University of New Mexico, Albuquerque, NM, 1977.

HINTON, L. Language planning. In: HINTON, L.; HALE, K. (ed.). The Green Book of Language Revitalization in Practice. Leiden: BRILL, 2001a. cap. 5, p. 51-73.

HINTON, L. Language revitalization: An overview. In: HINTON, L.; HALE, K. (ed.). The Green Book of Language Revitalization in Practice. Leiden: BRILL, 2001b. cap. 1, p. 3-18.

HINTON, L. The master-apprentice language learning program. In: HINTON, L.; HALE, K. (ed.). The Green Book of Language Revitalization in Practice. Leiden: BRILL, 2001c. cap. 17, p. 217-223.

HINTON, L. Teaching methods. In: HINTON, L.; HALE, K. (ed.). The Green Book of Language Revitalization in Practice. Leiden: BRILL, 2001d. cap. 14, p. 179-189. 
HINTON, L. et al. The master-apprentice language learning program. In: HINTON, L.; HUSS, L. M.; ROCHE, G. (ed.). The Routledge handbook of language revitalization. New York and London: Routledge, 2018. cap. 12, p. $127-136$.

HINTON, L.; HALE, K. The Green Book of Language Revitalization in Practice. Leiden: BRILL, 2001.

HINTON, L.; HUSS, L. M.; ROCHE, G. (ed.). The Routledge handbook of language revitalization. New York: NY: Routledge, 2018

HINTON, L.; MEEK, B. A. Language revitalization in indigenous North America. In: HINTON, L.; HUSS, L. M.: ROCHE, G. (ed.). The Routledge handbook of language revitalization. New York and London: Routledge, 2018. cap. 36, p. 375-383.

HORNBERGER, N. (ed.). Indigenous literacies in the Americas: language planning from the bottom up. Berlin: Mouton de Gruyter, 1996.

HORNBERGER, N. Frameworks and models in language planning and policy. In: RICENTO, T. (ed.). An Introduction to Language Policy: Theory and Methods. Malden, MA: Blackwell Publishing, 2006. cap. 2, p. $24-$ 41.

HORNBERGER, N. (ed.). Can Schools Save Indigenous Languages? Policy and practice on four continents. Hampshire-UK: Palgrave MacMillan, 2008. (Palgrave Studies in Minority Language and Communities).

HORNBERGER, N.; DE KORNE, H. Is revitalization through education possible? In: HINTON, L.; HUSS, L. M.; ROCHE, G. (ed.). The Routledge handbook of language revitalization. New York and London: Routledge, 2018. cap. 9 , p. $94-104$.

HUDSON, R. Sociolinguistics. 2nd. ed. Cambridge, UK: Cambridge University Press, 1996.

JACOBS, A. A chronology of Mohawk language instruction at Kahnawà:ke. In: GRENOBLE, L.; WHALEY, L. (ed.) Endangered Languages: Current issues and future prospects. Cambridge: Cambridge University Press, 1998. p. 117-123.

KING, J. Te Kohanga Reo: Maori language revitalization. In: HINTON, L.; HALE, K. (ed.). The Green Book of Language Revitalization in Practice. San Diego, CA: Academic Press, 2001. p. 119-128.

KRASHEN, S. D. Principles and Practice in Second Language Acquisition. New York: Pergamon Press, 1982.

LABOV, W. Principles of Linguistic Change: Social Factors. Cambridge: Blackwell Publishing, 2001.

LEITE, Y.; FRANCHETTO, B. 500 anos de línguas indígenas no Brasil. In: CARDOSO, S.; MOTA, J.; SILVA, R. V. M. e (ed.). Quinhentos Anos de História Linguística do Brasil. Salvador, Brasil: Secretaria da Cultura e Turismo do Estado da Bahia, 2006. p. 15-62.

LIMA, S. The Kawaiweté pedagogical grammar: Linguistic theory, collaborative language documentation, and the production of pedagogical materials. Language Documentation \& Conservation, v. 20, p. 54-72, 2020.

LO BIANCO, J. Reinvigorating language policy and planning for intergenerational language revitalization. In: HINTON, L.; HUSS, L. M.; ROCHE, G. (ed.). The Routledge handbook of language revitalization. New York and London: Routledge, 2018. cap. 4, p. 36-48.

MAIA, M. Manual de Linguística: Subsídios para a formação de professores indígenas na área da linguagem. Brasília, Brasil: MEC-Unesco, 2006a. (Vias dos Saberes, v. 4).

MAIA, M. A Revitalização de línguas indígenas e seu desafio para a educação intercultural bilíngue. Revista Tellus, n.11, p. 61-76, 2006b.

McCARTY, T. (ed.). Ethnography and Language Policy. New York: Routledge, 2011.

McCARTY, T. Language Planning and Policy in Native America: history, theory, praxis. Bristol, UK: Multilingual Matters, 2013.

McCARTY, T. Community-based language planning: Perspectives from indigenous language revitalization. In: HINTON, L.; HUSS, L. M.; ROCHE, G. (Ed.). The Routledge handbook of language revitalization. New York and London: Routledge, 2018. cap. 3, p. 22 -35. 
MICHAUD, L. N.; MCCOY, K. F. Empirical derivation of a sequence of user stereotypes for language learning. User Modeling and User-Adapted Interaction, Netherlands, v. 14, p. 317-350, 2004.

MILHOMEM, M. S. F. dos S. Educação escolar indígena: as dificuldades do currículo intercultural e bilíngue. Revista Fórum, v. 3, p. 95-102, 2011.

MOORE, D.; GALUCIO, A. V. Perspectives for the documentation of indigenous languages in Brazil. In: PÉREZ BÁEZ, G.; ROGERS, C.; LABRADA, J. E. R. (ed.). Language Documentation and Revitalization in Latin American Contexts. Berlin: Mouton de Gruyter, 2016, (Trends in Linguistics). cap. 2, p. 29-58.

MORAES DA SILVA, M. N. Parkatêjê Língua de Herança. Tese (Doutorado) - Universidade Federal do Pará, Belém-PA, 2019

MOSEL, U. Creating educational materials in language documentation projects: Creating innovative resources for linguistic research. In: SEIFART, F. et al. (ed.). Potentials of language documentation: Methods, analyses, and utilization. Honolulu: University of Hawaii Press, 2012, Language Documentation \& Conservation, v. 3. p. 111 $-117$.

NASCIMENTO, M.G. MAIA, M., WHAN, C. Kanhgág Vi Jagfe - Ninho de língua e cultura Kaingang na Terra Indígena Nonoai (RS) - Uma proposta de diálogo intercultural com o povo Maori da Nova Zelândia. Revista LinguíStica, v. 13, n.1, p. 367-383, 2017.

NATHAN, D.; FANG, M. Language documentation and pedagogy for endangered languages: A mutual revitalization. In: AUSTIN, P. (ed.). Language documentation and description. London, UK: SOAS, 2009. v. 6, p. 132-160.

OBONYO, V. et al. Digital smartpen techonology and revitalization of the Myaamia language. ACM Journal on Computing and Cultural Heritage, v. 4, n. 4, p. 1-11, 2011.

O'REGAN, H. M. Kotahi mano kaika, kotahi mano wawata - a thousand homes, a thousand dreams. In: HINTON, L.; HUSS, L. M.; ROCHE, G. (ed.). The Routledge handbook of language revitalization. New York and London: Routledge, 2018. cap. 10, p. 107-114.

PEARSON, B. Z. Raising a Bilingual Child: a step-by-step guide for parents. New York, NY: Living Language, 2008 .

PEARSON, B. Z.; AMARAL, L. Interactions between input factors in bi- lingual language acquisition: Considerations for minority language maintenance. In: PARADIS, J.; GRUTER, T. (ed.). Input and Experience in Bilingual Development. Amsterdam, The Netherlands: John Benjamins Publishing Company, 2014. p. 99-117.

PÉREZ BÁEZ, G. Addressing the gap between community beliefs and priorities and researchers' language maintenance interests. In: PÉREZ BÁEZ, G.; ROGERS, C.; LABRADA, J. E. R. (ed.). Language Documentation and Revitalization in Latin American Contexts. Berlin: Mouton de Gruyter, 2016, (Trends in Linguistics, v. 295). cap. 7, p. 165-194.

PÉREZ BÁEZ, G.; VOGEL, R.; PATOLO, U. Global survey of revitalization efforts: A mixed methods approach to understanding language revitalization practices. Language Documentation \& Conservation, v. 13, p. 446-513, 2019.

PETERS, M.; PETERS, T. Our kanienkéha language. In: HINTON, L. (ed.). Bringing our languages home: Language revitalization for families. Berkeley, CA: Heyday Books, 2013. p. 61-79.

RICE, K. Ethical issues in linguistic fieldwork: An overview. Journal of Academic Ethics, v. 4, p. 123-155, 2006

RICE, K. The linguist's responsibilities to the community of speakers: Practice and values. In: GRENOBLE, L.; FURBEE, N. (ed.). Language Documentation: Practice and Values. Amsterdam, The Netherlands: John Benjamins Publishing Co., 2010. p. 25-36.

RICE, K. Documentary linguistics and community relations. Language Documentation \& Conservation, v. 5, p. 187-207, 2011

SALLABANK, J. From language documentation to language planning: Not necessarily a direct route. In: SEIFART, F. et al. (ed.). Potentials of language documentation: Methods, analyses, and utilization. Honolulu: University of Hawaii Press, 2012, Language Documentation \& Conservation, v. 3. p. 118 - 125. 
SÁNCHEZ, L. The linguist gaining access to the indigenous populations: Sharing cultural and linguistic knowledge in South America. In: PÉREZ BAEZ, G..; ROGERS, C.; LABRADA, J. E. R. (ed.). Language Documentation and Revitalization in Latin American Contexts. Berlin: Mouton de Gruyter, 2016, (Trends in Linguistics). cap. 8, p. 195-213.

SANTOS GARCIA, S.; CRUZ, T. C. de la; AMARO, K. I. V. The revitalization of Wixarika: A community project in the midwest region of Mexico. In: BAEZ, G. P.; ROGERS, C.; LABRADA, J. E. R. (ed.). Language Documentation and Revitalization in Latin American Contexts. Berlin: Mouton de Gruyter, 2016, (Trends in Linguistics). cap. 4, p. 81-108.

SILVA, C.; AMARAL, L.; MAIA, M. Palavras-BO em Karajá: Como transmutar análises linguísticas formais em material pedagógico. Cadernos de Educação Escolar Indígena, v. 11, n. 1, p. 69-85, 2014

SILVA, J. I. Do mito da língua única à política do pluralismo linguístico: desafios na implementação de leis de cooficialização linguística em municípios brasileiros. Matraga, v. 23, n. 38, p. 223-241, 2016.

SKUTNABB-KANGAS, T. Linguistic genocide in education - or worldwide diversity and human rights? Mahwah, NJ: Lawrence Erlbaum, 2000.

SUGITA, Y. Language revitalization or language fossilization? Some suggestions for language documentation from the viewpoint of interactional linguistics. In: AUSTIN, P.; BOND, O.; NATHAN, D. (ed.). Proceedings of first conference on language documentation and linguistic theory. London, UK: SOAS, 2007. p. 243-250.

TSUNODA, T. Language Endangerment and Language Revitalization. Berlin - New York: Mouton de Gruyter, 2005. (Trends in Linguistics, v. 148).

WARNER, S. The movement to revitalize the Hawaiian language and culture. In: HINTON, L.; HALE, K. (ed.). The Green Book of Language Revitalization in Practice. San Diego, CA: Academic Press, 2001. p. 133-144.

WESCHE, M. B.; SKEHAN, P. Communicative, task-based, and content-based language instruction. In: KAPLAN, R. (ed.). The Oxford Handbook of Applied Linguistics. Oxford, UK: Oxford University Press, 2002. cap. 17, p. 207-228.

ZAHIR, Z. Language nesting in the home. In: HINTON, L.; HUSS, L. M.; ROCHE, G. (ed.). The Routledge handbook of language revitalization. New York and London: Routledge, 2018. cap. 15, p. 156-165.

ZÚÑIGA, M.; SÁNCHEZ, L.; ZACHARÍAS, D. Demanda y Necesidad de Educación Bilingüe. Lima - Peru: PLANCAD-GTZ, 2000. 